\title{
AECL/U.S. INERI - \\ Development of Inert Matrix \\ Fuels for Plutonium and \\ Minor Actinide Management \\ in Power Reactors - Fuel \\ Requirements and Down- \\ Select Report
}

William Carmack

Randy Fielding

Pavel Medvedev

Mitch Meyer

Michael Todosow

Holly Hamilton

Juan Nino

Simon Philpot

James Tulenko

August 2005

The INL is a U.S. Department of Energy National Laboratory operated by Battelle Energy Alliance 
INL/EXT-05-00560

\section{AECL/U.S. INERI - Development of Inert Matrix Fuels for Plutonium and Minor Actinide Management in Power Reactors - Fuel Requirements and Down- Select Report}

${ }^{\mathrm{a}} \mathrm{INL}$

${ }^{\mathrm{b}} \mathrm{BNL}$

${ }^{\mathrm{c}} \mathrm{AECL}$

${ }^{\mathrm{d}}$ University of Florida

\author{
William Carmack ${ }^{\mathrm{a}}$ \\ Randy Fielding ${ }^{a}$ \\ Pavel Medvedev ${ }^{\mathrm{a}}$ \\ Mitch Meyer $^{\mathrm{a}}$ \\ Michael Todosow ${ }^{b}$ \\ Holly Hamilton ${ }^{c}$ \\ Juan Nino ${ }^{d}$ \\ Simon Philpot ${ }^{\mathrm{d}}$ \\ James Tulenko ${ }^{d}$
}

August 2005

Idaho National Laboratory

Idaho Falls, Idaho 83415

Prepared for the

U.S. Department of Energy

Office of Nuclear Energy

Under DOE Idaho Operations Office

Contract DE-AC07-05ID14517 



\begin{abstract}
This report documents the first milestone of the International Nuclear Energy Research Initiative (INERI) U.S./Euratom Joint Proposal 1.8 entitled "Development of Inert Matrix Fuels for Plutonium and Minor Actinide Management in Light-Water Reactors." The milestone represents the assessment and preliminary study of a variety of fuels that hold promise as transmutation and minor actinide burning fuel compositions for light-water reactors. The most promising fuels of interest to the participants on this INERI program have been selected for further study. These fuel compositions are discussed in this report.
\end{abstract}




\section{CONTENTS}

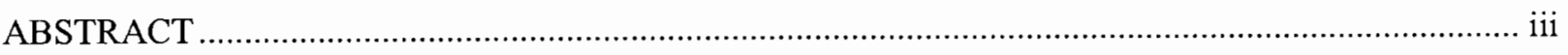

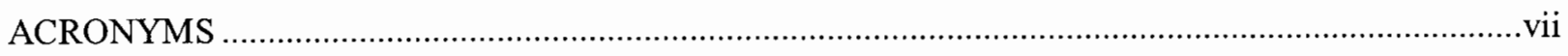

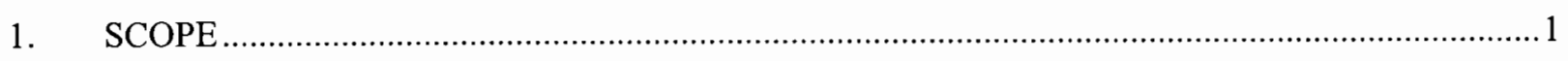

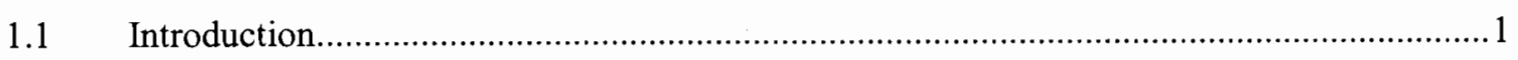

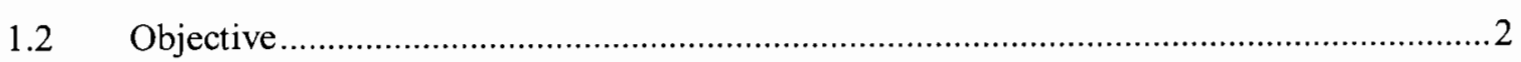

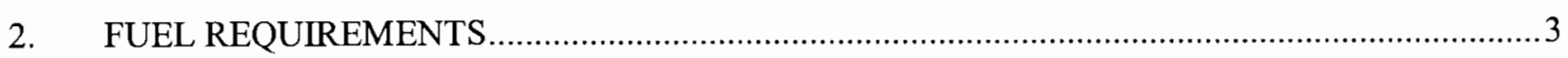

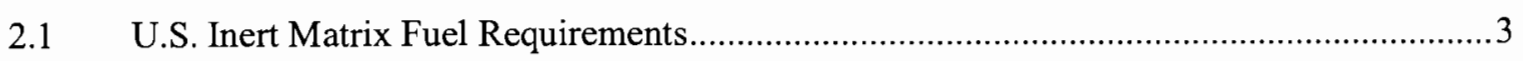

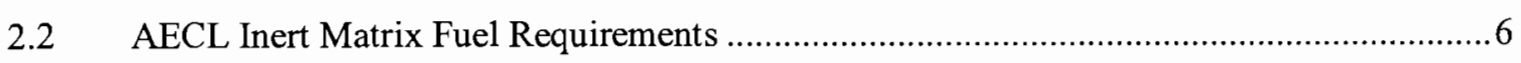

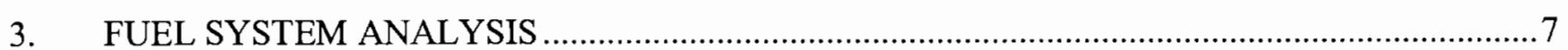

3.1 Neutronic Performance Analysis of Candidate IMF Systems ...........................................

3.2 Thermal Performance Analysis of Candidate IMF Systems ............................................ 8

3.3 Transient/Safety Analysis of Candidate IMF Systems ......................................................

4. FUEL SYSTEM FABRICATION DEVELOPMENT …....................................................... 14

4.1 MOX-Minor Actinide Fuel Development .................................................................... 14

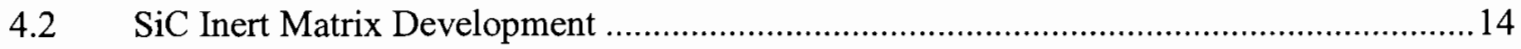

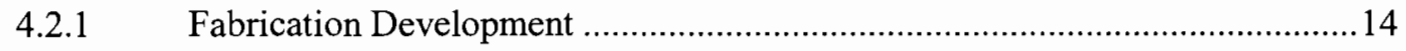

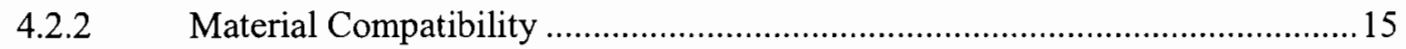

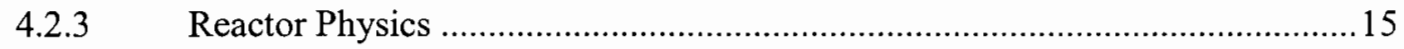

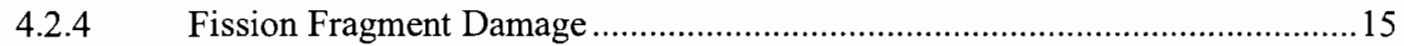

4.3 Dual Phase $\mathrm{MgO}-\mathrm{ZrO}_{2}$ Inert Matrix Development ......................................................16

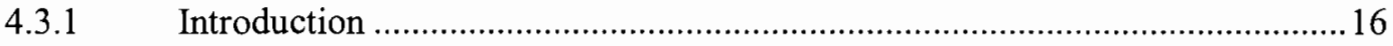

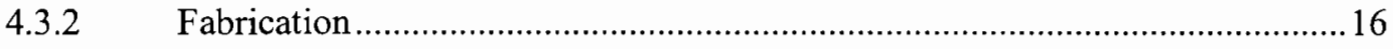

4.3.3 Characterization of $\mathrm{MgO}-\mathrm{ZrO} 2-\mathrm{PuO}_{2}$ ceramics ............................................. 17

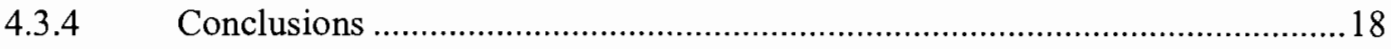

4.4 Advanced Pyrochlore Inert Matrix Development............................................................22

4.5 Zr Metal Inert Matrix Dispersion Fuel Development ....................................................25

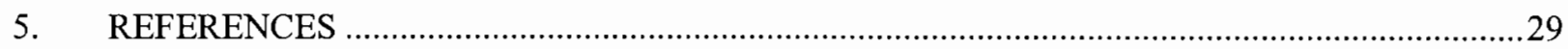

\section{FIGURES}

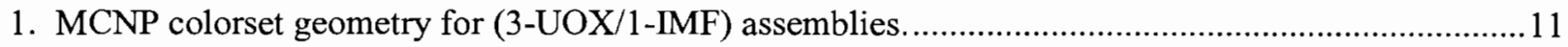

2. Kinf vs. full power day burnup graph comparison with Np-Pu-Am-MOX and UOX …....................11

3. Peak clad temperature for hot pin comparison between $\mathrm{MOX}$ and $\mathrm{ZrO}_{2} / \mathrm{MgO}$ and $\mathrm{SiC}$ inert matrix materials 
4. Peak clad temperature for hot pin for Loss of Power and Loss of Primary Flow transient...................12

5. Reactor power under loss of flow transient................................................................................... 12

6. Core average fuel temperature under loss of flow..................................................................... 13

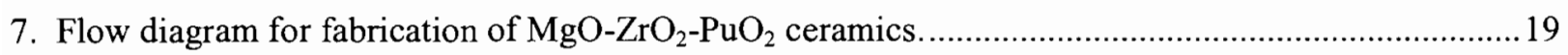

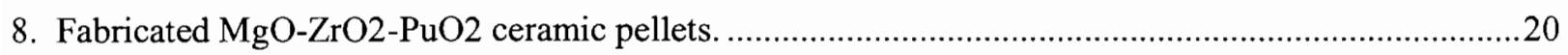

9. SEM image of the $\mathrm{MgO}-\mathrm{ZrO}_{2}-\mathrm{PuO}_{2}$ ceramic sample submitted for analysis..................................20

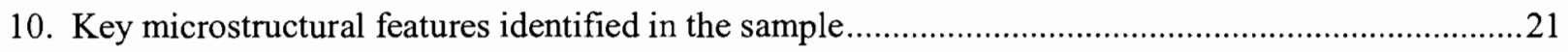

11. Typical EDS spectra observed in various locations in the ceramic...............................................21

12. Unit cell of the fluorite crystal structure $\left(\mathrm{BO}_{2}\right)$ and one-eighth of the unit cell of the pyrochlore

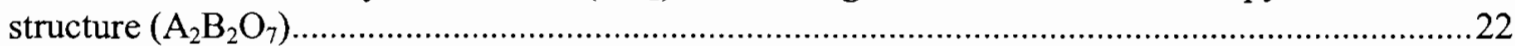

13. Experiment and atomistic simulations show that increasing the $B$ cation radius lowers the anti-site defect energy and, hence, decreases the amount of radiation damage .........................................23

14. Calculated thermal conductivity map for forty different $\mathrm{A}_{2} \mathrm{~B}_{2} \mathrm{O}_{7}$ pyrochlores..............................24

15. Schematic representation of the assembled Zr-4/Zr billet...........................................................27

16. Photograph of 0.4-in. diameter Zr matrix dispersion "fuel" extrusion..............................................22

17. Photograph of 0.4-in. diameter Zr matrix dispersion "fuel" extrusion longitudinal cross section.

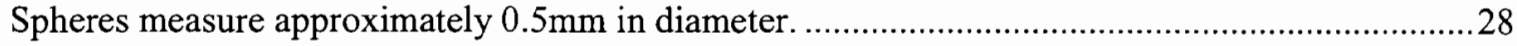

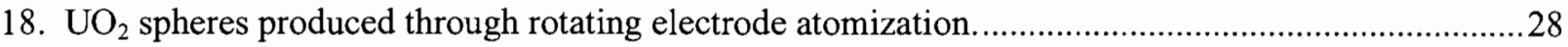

\section{TABLES}

1. Proposed compositions to be included in the LWR-2 irradiation test.............................................6

2. Reactivity coefficients and control worths for Westinghouse $17 \times 17$ assembly for

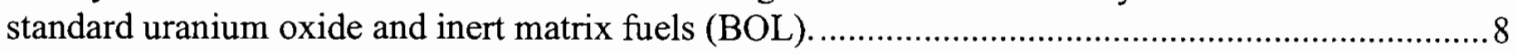

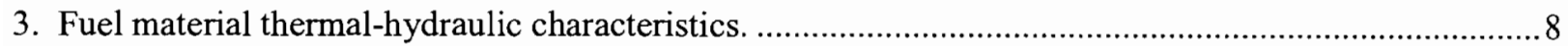

4. Dimensions and weight of the sintered $\mathrm{MgO}-\mathrm{ZrO}_{2}-\mathrm{PuO}_{2}$ ceramic pellets. .........................................22

5. Results from SEM EDS semi-quantitative analysis. Note that the ISIS EDS system cannot perform quantitative analysis for elements heavier than uranium. 


\section{ACRONYMS}

$\begin{array}{ll}\text { ACR } & \text { Advanced CANDU Reactor } \\ \text { AECL } & \text { Atomic Energy Canada Ltd } \\ \text { AFCI } & \text { Advanced Fuel Cycle Initiative } \\ \text { EDS } & \text { Energy Dispersive X-ray Spectroscopy } \\ \text { IMF } & \text { inert-matrix fuel } \\ \text { LWR } & \text { light-water reactor } \\ \text { MDNBR } & \text { minimum departure from nucleate boiling ratio } \\ \text { MOX } & \text { mixed oxide } \\ \text { MTC } & \text { moderator temperature coefficient } \\ \text { OTTO } & \text { once-through then out } \\ \text { PCT } & \text { peak clad temperature } \\ \text { SEM } & \text { scanning electron microscopy } \\ \text { SNF } & \text { spent nuclear fuel } \\ \text { TRU } & \text { transuranic } \\ \text { UOX } & \text { uranium-oxide } \\ \text { YSZ } & \text { Yttria stabilized zirconia }\end{array}$


viii 


\section{AECL/U.S. INERI - Development of Inert Matrix Fuels for Plutonium and Minor Actinide Management in Power Reactors Fuel Requirements and Down-Select Report}

\section{SCOPE}

\subsection{Introduction}

The U.S. Advanced Fuel Cycle Program and the Atomic Energy Canada Ltd (AECL) seek to develop and demonstrate the technologies needed to minimize the overall $\mathrm{Pu}$ and minor actinides present in the light-water reactor (LWR) nuclear fuel cycles. It is proposed to reuse the Pu from LWR spent fuel both for the energy it contains and to decrease the hazard and proliferation impact resulting from storage of the $\mathrm{Pu}$ and minor actinides. The use of fuel compositions with a combination of $\mathrm{U}$ and $\mathrm{Pu}$ oxide (mixed oxide [MOX]) has been proposed as a way to recycle $\mathrm{Pu}$ and/or minor actinides in LWRs. It has also been proposed to replace the fertile $\mathrm{U}^{238}$ matrix of MOX with a fertile-free matrix (inert-matrix fuel [MF]) to reduce the production of $\mathrm{Pu}^{239}$ in the fuel system. It is important to demonstrate the performance of these fuels with the appropriate mixture of isotopes and determine what impact there might be from trace elements or contaminants. Previous work has already been done to look at weapons-grade Pu in the MOX configuration [1][2] and the reactor-grade $\mathrm{Pu}$ in a MOX configuration including small (4000 ppm additions of Neptunium). This program will add to the existing database by developing a wide variety of MOX fuel compositions along with new fuel compositions called inert-matrix fuel (IMF). The goal of this program is to determine the general fabrication and irradiation behavior of the proposed IMF fuel compositions. Successful performance of these compositions will lead to further selection and development of IMF for use in LWRs. This experiment will also test various inert matrix material compositions with and without quantities of the minor actinides Americium and Neptunium to determine feasibility of incorporation into the fuel matrices for destruction.

There is interest in the U.S. and world-wide in the investigation of IMFs for scenarios involving stabilization or burn down of plutonium in the fleet of existing commercial power reactors. IMF offers the potential advantage for more efficient destruction of plutonium and minor actinides relative to MOX fuel. Greater efficiency in plutonium reduction results in greater flexibility in managing plutonium inventories and in developing strategies for disposition of minor actinides, as well as a potential for fuel cycle cost savings. Because fabrication of plutonium-bearing (and minor actinide-bearing) fuel is expensive relative to $\mathrm{UO}_{2}$ in terms of both capital and production, cost benefit can be realized through a reduction in the number of plutonium-bearing elements required for a given burn rate. In addition, the choice of matrix material may be manipulated either to facilitate fuel recycling or to make plutonium recovery extremely difficult. In addition to plutonium/actinide management, an inert matrix fuel having high thermal conductivity may have operational and safety benefits; lower fuel temperatures could be used to increase operating and safety margins, uprate reactor power, or a combination of both.

The CANDU reactor offers flexibility in plutonium management and minor actinide burning by virtue of on-line refueling, a simple bundle design, and good neutron economy. A full core of inert matrix fuel containing either plutonium or a plutonium-actinide mix can be utilized, with plutonium destruction efficiencies greater than $90 \%$, and high ( $>60 \%)$ actinide destruction efficiencies. The Advanced CANDU Reactor (ACR) could allow additional possibilities in the design of an IMF bundle, since the tighter lattice pitch and light-water coolant reduce or eliminate the need to suppress coolant void reactivity, allowing the center region of the bundle to include additional fissile material and to improve 
actinide burning. The ACR would provide flexibility for management of plutonium and minor actinides from the existing LWR fleet, and would be complementary to the Advanced Fuel Cycle Initiative (AFCI) program in the U.S. Many of the fundamental principles concerning the use of IMF are nearly identical in LWRs and the ACR, including fuel/coolant compatibility, fuel fabrication, and fuel irradiation behavior. In addition, the U.S. and Canada both have interest in development of Generation IV supercritical water reactor technology, to which this fuel type would be applicable for plutonium and minor actinide management. An inert matrix fuel with high thermal conductivity would be particularly beneficial to any supercritical water reactor concept. Given these similarities, it is proposed that a joint project be conducted within the framework of a U.S.-Canada INERI project on IMF.

\subsection{Objective}

This report will present analysis of the inert matrix fuel compositions of interest for application to U.S. and Canadian LWR fuel cycles, report on the development of fabrication procedures for these compositions, and provide an overview of the test and demonstration plan for these fuel systems.

This report serves in fulfillment of the first deliverable and milestone for the joint INERI program. 


\section{FUEL REQUIREMENTS}

\subsection{U.S. Inert Matrix Fuel Requirements}

Currently, commercial reactors in the U.S. operate on the once-through cycle, with the spent nuclear fuel (SNF) eventually destined for long-term storage in a geologic repository. Since the transuranic (TRU) elements in the SNF present a proliferation risk, limit the loading in the repository, and are the major contributors to the long-term toxicity and dose from the repository, the AFCI program is studying ways to reduce the amount of TRU that will eventually require storage. Several options to achieve this objective are being examined in the AFCI program, including "burning" the TRU in commercial LWRs and fast reactors. Fuel forms under consideration for LWRs include MOX and IMF. Low fertile IMF has been proposed for use in many forms and studied by several researchers. Inert matrix fuel offers several advantages relative to MOX, principally a greater degree of reduction in the TRU since no new TRU is produced in this fuel form. Currently, the AFCI LWR transmutation fuel development program plans to test both MOX and MF in an irradiation test, designated LWR-2, in the United States Advanced Test Reactor, located at the Idaho National Laboratory. The goal of the AFCI LWR transmutation program is to develop a fuel composition that fulfills four general criteria:

1. The fuel must provide for reliable power production in a LWR similarly to standard uranium-oxide (UOX) fuel.

2. The fuel composition must provide for the destruction of actinide species $(\mathrm{Pu}, \mathrm{Am}$, and $\mathrm{Np})$ in a proliferation resistant form.

3. The fuel must perform these functions without greatly increasing the fissile material loading (which affects fuel cycle cost) in the overall nuclear fuel cycle, and should be within the existing safety envelope of commercial LWRs.

4. The fuel composition must allow for extraction and processing to recover the heavy metal for possible further destruction (via recycling into LWRs or fast reactors) or treatment for ultimate burial in a geologic repository.

To provide for flexibility in the incorporation of plutonium/actinide bearing fuels in pressurized and boiling water reactors, a variety of MOX and IMF compositions are being proposed for inclusion in the planned AFCI irradiation experiment, LWR-2. A variety of compositions are needed to determine the feasibility and performance of fuels containing significant amounts of TRU, and allow for flexibility in loading strategies for fuel management. This paper will explore the general neutronic and thermal hydraulic performance of transmutation fuels based on the low fertile matrix material $\mathrm{MgO}-\mathrm{ZrO}_{2}$. For comparison the neutronic and thermal hydraulic performance characteristics of UOX, Yittria-Stabilized $\mathrm{ZrO}_{2}$ and $\mathrm{SiC}$ fuels are presented.

A variety of inert matrix materials have been proposed and studied for use in high burnup actinide fuel systems. Chang and Ryskamp0 proposed inert matrix fuel pins inter-dispersed in standard $\mathrm{LWR} \mathrm{UO}_{2}$ fuel bundles to achieve burnup and destruction of Pu material without negatively impacting operational characteristics of LWR operation. Herring et al.0 proposed a $\mathrm{ThO}_{2}$ based transmutation fuel for LWR systems to eliminate the $\mathrm{U}^{238}$ matrix from the reactor system entirely. Eaton, et al.0 proposed a full inert matrix of $\mathrm{ZrO}_{2}$ stabilized with $\mathrm{CaO}$ and loaded with TRU. Much work has been performed in the $\mathrm{YtO}$ stabilized $\mathrm{ZrO}_{2}$ matrix system for application to once-through then out (OTTO) fuel cycles, Schram0 and Ledergerber0. Irradiation and property test programs performed on the Yttria stabilized zirconia (YSZ) matrix have indicated excellent stability and performance both as a fuel system and as a final waste form meeting repository waste disposal criteria. In a once through fuel application Hellwig et al.0 irradiated a 
Yittria stabilized $\mathrm{ZrO}_{2}$ matrix. The study compositions attained $440 \mathrm{kWd} / \mathrm{cm}^{3}$ burnup with no measurable fission gas release. The composition densified to $100 \% \mathrm{TD}$ and pellet centerline temperature was found to be approximately 300 to $400^{\circ} \mathrm{C}$ higher than a comparable MOX fuel center-line temperature.

To implement an inert matrix fuel composition in the U.S. commercial LWR fleet, the matrix composition must be stable in water, and have a thermal conductivity higher than that found in the cubic $\mathrm{ZrO}_{2}$. Preliminary property tests and fabrication trials by Medvedev 0,0 at the Idaho National Laboratory have indicated that the performance of a dual-phase $\mathrm{MgO}-\mathrm{ZrO}_{2}$ matrix may be able to meet the requirements of the AFCI LWR fuel program. The AFCI LWR fuel development program intends to fabricate and test a variety of fuel $\mathrm{MgO}-\mathrm{ZrO}_{2}$ compositions in an irradiation campaign in the Advanced Test Reactor in late 2006. The test will contain both IMF compositions and MOX fuel compositions for comparison. Some of the tested compositions will also include americium and neptunium to investigate effect of minor actinides on the fuel matrices.

Fuel compositions actually employed in LWR transmutation fuels will be significantly affected by what TRU streams can be easily extracted in the separations process. The "natural" streams are $\mathrm{Pu}$ (which would not be allowed from proliferation concerns), $\mathrm{Np}+\mathrm{Pu}$ (which is considered to have enhanced proliferation resistance; this fuel will result in some $\mathrm{Am}$ being present from the decay of $\mathrm{Pu}^{241}$ after separation thru fabrication and prior to reactor insertion), and $\mathrm{Np}+\mathrm{Pu}+\mathrm{Am}$. Current plans do not envision the inclusion of Curium. 
Table Table 1 presents a summary of the currently planned fuel compositions in the LWR-2 test series.

The $\mathrm{MgO}-\mathrm{ZrO}_{2}$ dual phase ceramic provides a combination of the properties of $\mathrm{MgO}$ and of $\mathrm{ZrO}_{2}$ that may be able to fulfill the goals of the U.S. LWR transmutation fuel program. When combined in the dual phase ceramic, the high thermal conductivity of $\mathrm{MgO}$ tends to overcome the poor thermal conductivity of $\mathrm{ZrO}_{2}$, Medvedev 0 . The addition of $\mathrm{MgO}$ to $\mathrm{ZrO}_{2}$ in significant quantity has been found to increase the thermal conductivity of the matrix material greater than standard UOX or MOX fuel compositions. The stability of $\mathrm{ZrO}_{2}$ in water tends to overcome the dissolution of $\mathrm{MgO}$ in water. Having the ability to balance the thermal conductivity of the fuel with the capability for dissolution makes the $\mathrm{MgO}-\mathrm{ZrO}_{2}$ ceramic a leading candidate for an inert matrix material. $\mathrm{MgO}$ and $\mathrm{ZrO}_{2}$ both are known to have acceptable irradiation performance and demonstrating the performance of a Pu-bearing $\mathrm{MgO}-\mathrm{ZrO}_{2}$ fuel composition with additions of $\mathrm{Am}$ and $\mathrm{Np}$ will facilitate selection of this composition for further development as a transmutation fuel for LWRs.

Due to the fission efficiency of reactor grade plutonium the use of burnable poisons will likely be required to control excess reactivity throughout the fuel life, control the power distribution within an acceptable range, and provide additional Doppler feedback in inert matrix fuel compositions. Erbium oxide may be added to the inert matrix fuel compositions to achieve these objectives. Porta and Asou0, recommend less than $3 \mathrm{wt} \%$ additions of erbia to the fuel matrix since additions of erbia tend to decrease thermal conductivity. Medvedev0 measured a depression in thermal conductivity of $\mathrm{MgO}-\mathrm{ZrO}_{2}$ with erbia additions and therefore these additions must be balanced.

To study these issues, a neutronic/thermal-hydraulic/transient screening analysis is conducted. The following sections present the analysis methodology and the results as applied to inert matrix compositions of interest with emphasis on the $\mathrm{MgO}-\mathrm{ZrO}_{2}$ system. 
Table 1. Proposed compositions to be included in the LWR-2 irradiation test.

\begin{tabular}{|c|c|c|}
\hline & Description & Composition \\
\hline 2 pins & LWR-1 a composition at high burnup & $(\mathrm{U}, \mathrm{Pu}) \mathrm{O}_{2}$ \\
\hline 2 pins & IMF replacement to MOX matrix & $(\mathrm{Pu}) \mathrm{O}_{2}-\mathrm{MgO}_{2} \mathrm{ZrO}_{2}$ \\
\hline 2 pins & IMF replacement to MOX matrix, w/ $\mathrm{Np}$ addition & $(\mathrm{Pu}, \mathrm{Np}) \mathrm{O}_{2},{\mathrm{MgO}-\mathrm{ZrO}_{2}}$ \\
\hline 2 pins & MOX w/ Np,Am additions & $(\mathrm{U}, \mathrm{Pu}, \mathrm{Np}, \mathrm{Am}) \mathrm{O}_{2}$ \\
\hline 2 pins & IMF replacement to MOX w/Np, Am additions & $(\mathrm{Pu}, \mathrm{Np}, \mathrm{Am}) \mathrm{O}_{2}, \mathrm{MgO}-\mathrm{ZrO}_{2}$ \\
\hline 1 pin & Silicon carbide inert matrix & $\mathrm{UO}_{2}-\mathrm{SiC}$ \\
\hline 1 pin & Advanced Pyrochlore 1 & $(\mathrm{Pu}) \mathrm{O}_{2}-\mathrm{MgO}-\mathrm{ZrO}_{2}-\mathrm{Nd}$ \\
\hline 1 pin & Advanced Pyrochlore 2 & $(\mathrm{Pu}) \mathrm{O}_{2}-\mathrm{MgO}-\mathrm{ZrO}_{2}-\mathrm{Yb}$ \\
\hline
\end{tabular}

\subsection{AECL Inert Matrix Fuel Requirements}

The requirements of an $\mathrm{IMF}$ for use in $\mathrm{CANDU}^{\circledR}$ stem from three areas; performance, Pu/actinide destruction, and waste management. As a base case, the IMF should perform at least as well as $\mathrm{UO}_{2}$ under normal and accident scenarios. Performance parameters include reactor control, bundle power, fuel temperature, gas release, sheath strain, compatibility with cladding and coolant, pellet mechanical integrity and irradiation stability (resistance to swelling from neutron and fission-fragment damage). No acceptance criterion has been established with regards to MF Pu/actinide destruction. Performance in this area can only be qualitatively assessed. Maximizing the percentage of Pu/actinide destruction achievable in a once-through cycle is clearly desirable. AECL has only considered a once-through fuel cycle to date. For the once-through cycle, the discharged IMF fuel must be suitable for direct deepgeological disposal. Since the exterior fuel design is the same as standard CANDU ${ }^{\circledR}$ fuel, this has been studied extensively. As with in-reactor performance, the suitability of the IMF as a waste form must be shown to be as good, or better than irradiated $\mathrm{UO}_{2}$ under similar conditions.

The operational and material requirements of an IMF for use in CANDU ${ }^{\circledR 8}$ are very similar to those in a LWR. This was one of the driving forces for the INERI collaboration. AECL had conducted a material selection process prior to the initiation of this project and had selected $\mathrm{SiC}$ as the matrix material for further investigation. The initial down selection was based on the following attractive properties of $\mathrm{SiC}$ :

- Demonstrated structural stability in a neutron flux

- High thermal conductivity

- Small neutron capture cross section

- Relatively inert.

While these features made $\mathrm{SiC}$ attractive as a matrix material for an $\mathrm{IMF}$, there were material compatibility and reactor physics aspects that were unknown, and standard fabrication practices for $\mathrm{SiC}$ at that time were not amenable to mass production.

A research program was set up to investigate the aforementioned unknowns. A contract was established with Queens University in Kingston, Ontario to investigate methods of producing highdensity, SiC-based pellets via pressure-less sintering at lower temperatures. The results of the research are summarized in Section 4.2. 


\section{FUEL SYSTEM ANALYSIS}

To screen candidate inert matrix fuel compositions for potential use in LWRs an integrated methodology is used which considers neutronic, thermal-hydraulic, and transient/accident aspects. This paper presents the results of this screening analysis performed on one of the above inert matrix compositions $\left((\mathrm{Np}+\mathrm{Pu}+\mathrm{Am}) \mathrm{O}_{2}, \mathrm{MgO}-\mathrm{ZrO}_{2}\right)$, and compares the results to an analysis performed in a previous study by Todosow et al.0 which considered the same fuel with $\mathrm{UOX}, \mathrm{ZrO}_{2}$, and $\mathrm{SiC}$ matrix materials.

The reference core for this analysis is a typical 4-loop Westinghouse pressurized water reactor (PWR) with a power of $3400 \mathrm{MW}(\mathrm{th})$ and 193-17 $\times 17$ fuel assemblies. The reference fuel is low enriched $(<5 \mathrm{w} / \mathrm{o}) \mathrm{U}^{235}$ uranium oxide capable of achieving an 18-month cycle, and a typical fuel management strategy with three batches, and once through then out with geological repository storage for the discharged SNF. Neutronic calculations are limited to an infinite array of fuel assemblies, and "colorset" geometries that model the four neighboring quadrants of four neighboring assemblies. Figure 1 is a colorset geometry representing three UOX assemblies and one MF assembly. Note that the IMF assembly (upper-right) assumes an annular fuel rod with a central plug to compensate for the possible lower thermal conductivity of the inert matrix. While this is true for a pure $\mathrm{ZrO}_{2}$ matrix, it may not be necessary with other matrix materials as discussed earlier. The IMF fuel in all cases is assumed to contain $\mathrm{Np}, \mathrm{Pu}$, and $\mathrm{Am}$ in oxide form, with an isotopic distribution characteristic of the discharge fuel from an advanced LWR with a burnup of $\sim 50 \mathrm{GWd} / \mathrm{T}$, after seven years of cooling and post-fabrication. The neutronics calculations are supplemented by steady-state thermal-hydraulics, and selected system transient/accident analyses. Using the results of these analyses, preliminary conclusions can be drawn regarding the viability of proposed $\mathrm{IMF}$ with respect to conventional ( $\mathrm{Pu}$-only) and modified (e.g., $\mathrm{Np}+\mathrm{Pu}, \mathrm{Np}+\mathrm{Pu}+\mathrm{Am}) \mathrm{MOX}$ and UOX fueled cores.

\subsection{Neutronic Performance Analysis of Candidate IMF Systems}

The reactor physics calculations presented here were carried out with the BOXER lattice physics code 0 with nuclear data based on JEF1.1. The BOXER code and models have been extensively benchmarked against several standard nuclear design codes, with a variety of nuclear data libraries to qualify its use for these analyses. The analyses include evaluation of the moderator temperature coefficient (MTC), Doppler coefficient, soluble boron reactivity worth, coolant void coefficient, and control rod system reactivity worth, and reactivity versus burnup. Rod-wise power distributions and kinetics parameters are also determined for use in the thermal-hydraulic and safety analyses. Kinetics parameters include: prompt neutron lifetime, delayed neutron fraction, and decay constant.

Results are shown in Figure 2 for the burnup in full power day verses the $K_{\text {inf }}$ behavior for several matrix compositions of interest. Since the actinide loading for all IMF cases is the same, the results show that impact of different matrix materials on the cycle length is slight.

In addition to the achievable cycle length, typical reactivity and control coefficients were also evaluated and are shown in Table 2. The presence of Pu and other TRU isotopes is known to "degrade" some of these parameters relative to a conventional UOX-fueled system. In particular, the worth of soluble boron and control rods decreases with increasing loading of $\mathrm{Pu}$ and other TRU, and at sufficiently high loadings, the void coefficient becomes positive. Also shown are results for an IMF assembly with reactor-grade plutonium that is based on that employed in a full-core PWR design proposed by the Paul Scherrer Institute, as well as representative values for a reactor-grade-Pu MOX assembly, and from the Safety Analysis Report. The results show that, as expected, the most significant impact of IMF fuel is a significant reduction in the Doppler coefficient due to the absence of fertile material like U-238, and the 
soluble boron worth relative to conventional uranium oxide fuel; the MTC and void coefficients do not differ significantly. The results for zirconium oxide and silicon carbide matrix materials are very similar. The IMF results with TRU for the MTC, the void coefficient, and the estimated control rod (Ag-In-Cd) are close to those obtained by the Paul Scherrer Institute. The Doppler coefficient is less negative, while the soluble boron worth is more negative than for the Paul Scherrer Institute design. These results suggest a TRU-IMF design similar to that considered here is feasible/viable for implementation in a LWR. The behavior for an $\mathrm{MgO}-\mathrm{ZrO}_{2}$ matrix is similar to the other MMF results. These results suggest that mixed cores of IMF and UOX assemblies are the most likely implementation approach in order to keep an existing LWR within its licensed safety envelope.

Table 2. Reactivity coefficients and control worths for Westinghouse 17 x 17 assembly for standard uranium oxide and inert matrix fuels (BOL).

\begin{tabular}{|c|c|c|c|c|c|c|}
\hline \multirow[b]{2}{*}{ Reactivity Coefficients } & \multirow[b]{2}{*}{$\begin{array}{c}4.3 \mathrm{w} / \mathrm{o} \\
\mathrm{UOX}\end{array}$} & \multicolumn{2}{|c|}{$\mathrm{Np}+\mathrm{Pu}+\mathrm{Am}$ from $\mathrm{ALWR}$} & \multirow{2}{*}{$\begin{array}{l}\text { Paul Scherrer } \\
\text { Institute IMF } \\
\text { Reactor-grade } \\
\text { Pu-Zr-Er)O }\end{array}$} & \multirow{2}{*}{$\begin{array}{c}\text { MOX } \\
(7 \text { w/o of } \mathrm{Pu})\end{array}$} & \multirow{2}{*}{$\begin{array}{c}\text { Ref. Safety } \\
\text { Analysis } \\
\text { Report }\end{array}$} \\
\hline & & $(\mathrm{TRU}-\mathrm{Zr}) \mathrm{O}_{2}$ & $(\mathrm{TRU}) \mathrm{O}_{2}-\mathrm{SiC}$ & & & \\
\hline \multicolumn{7}{|l|}{ No Soluble Boron } \\
\hline Void $(\mathrm{pcm} / \%$ void $)$ & -139 & -106 & -109 & -105 & -105 & \\
\hline $\operatorname{MTC}\left(\mathrm{pcm} /{ }^{\circ} \mathrm{C}\right)$ & -37 & -33 & -33 & -35 & -41 & 0 to -72 \\
\hline Doppler $\left(\mathrm{pcm} /{ }^{\circ} \mathrm{C}\right)$ & -2.5 & -1.3 & -1.4 & -1.8 & -2.9 & $\begin{array}{l}-5.2 \text { to } \\
-2.5 \\
\end{array}$ \\
\hline Boron Worth $(\mathrm{pcm} / \mathrm{ppm})$ & -8 & -3.1 & -3.1 & -2.4 & -2 & -16 to -8 \\
\hline $\begin{array}{l}\text { Estimated } 61 \text { control rods } \\
\text { worth }(\% \Delta \rho)\end{array}$ & -10 & -6 & -6 & -6 & & $\begin{array}{l}-9 \text { (BOC) to } \\
-8.5 \text { (EOC) }\end{array}$ \\
\hline \multicolumn{7}{|l|}{$500 \mathrm{ppm}$ of Soluble Boron } \\
\hline Void ( $\mathrm{pcm} / \%$ void) & -94 & -85 & -90 & -88 & & \\
\hline $\mathrm{MTC}\left(\mathrm{pcm} /{ }^{\circ} \mathrm{C}\right)$ & -24 & -26 & -27 & -30 & & \\
\hline
\end{tabular}

Table 3. Fuel material thermal-hydraulic characteristics.

\begin{tabular}{|l|l|l|l|}
\hline \multicolumn{1}{|c|}{ Parameters } & \multicolumn{1}{|c|}{$\begin{array}{c}\text { PWR } \\
\left(\mathrm{UO}_{2}\right)\end{array}$} & \multicolumn{1}{c|}{$\begin{array}{c}\mathrm{IMF} \\
\left(\mathrm{ZrO}_{2} / \mathrm{MgO}\right)\end{array}$} & \multicolumn{1}{c|}{$\begin{array}{c}\text { IMF } \\
(\mathrm{SiC})\end{array}$} \\
\hline Hot Pin Radial Peaking & $\begin{array}{l}1.674 \\
(1.5678 \times 1.068)\end{array}$ & $\begin{array}{l}1.980 \\
(1.5678 \times 1.263)\end{array}$ & $\begin{array}{l}1.980 \\
(1.5678 \times 1.263)\end{array}$ \\
\hline $\begin{array}{l}\text { Fuel Thermal } \\
\text { Conductivity, W/m-K }\end{array}$ & $\begin{array}{l}5.14(\text { at } 616 \mathrm{~K}) \\
2.98(\text { at } 1200 \mathrm{~K})\end{array}$ & 5 (constant) & $\begin{array}{l}25.12(\text { at } 673 \mathrm{~K}) \\
16.12(\text { at } 1273 \mathrm{~K})\end{array}$ \\
\hline $\begin{array}{l}\text { Fuel Volumetric Heat } \\
\text { Capacity, } \mathrm{J} / \mathrm{m}^{3}-\mathrm{K}\end{array}$ & $\begin{array}{l}3.14 \times 10^{6}(\text { at } 673 \mathrm{~K}) \\
\left.3.44 \times 10^{6} \text { (at } 1373 \mathrm{~K}\right)\end{array}$ & $\begin{array}{l}4.22 \times 10^{6} \\
\text { (constant) }\end{array}$ & $3.37 \times 10^{6}($ at $600 \mathrm{~K})$ \\
\hline
\end{tabular}

\subsection{Thermal Performance Analysis of Candidate IMF Systems}

The thermal-hydraulic performance of a three UOX/1-IMF "colorset" assembly configuration was evaluated by using the COBRA-EN code 0 . Minimum departure from nucleate boiling ratio (MDNBR) is used as a figure of merit for the margin to thermal limits in the hottest or highest power region of the core. The thermal conductivity of the fuel matrix does not enter into this analysis due to the steady state nature 
of the heat transfer. The MDNBR generally depends on the temperature of the clad surface at steady state which is dependent upon the heat generation rate in the fuel.

Table 3 presents a summary of the primary heat transfer parameters for the $\mathrm{UO}_{2}, \mathrm{MgO}-\mathrm{ZrO}$, and $\mathrm{SiC}$. The thermal conductivity of the fuel matrix does not greatly affect the MDNBR analysis due to the steady state nature of the analyses. The MDNBR generally depends on the temperature of the clad surface at steady-state which is dependent upon the heat generation rate found in the fuel. The heat generation rate depends on the fissile loading and the neutron density found in the reactor core. Hence, the matrix material generally only has an effect on the MDNBR as a result in changes in the power distribution. The analysis conducted for the purpose of this paper has found that the matrices of interest do not greatly affect the performance of the fuel when compared to a standard MOX composition. MOX is known however to generally operate from 200 to $300^{\circ} \mathrm{C}$ greater than a comparable UOX composition 0 .

\subsection{Transient/Safety Analysis of Candidate IMF Systems}

Transient/safety analyses are performed using the RELAP5-3D systems computer code [14] modeling selected scenarios taking a four-loop PWR plant as the model. Accidents that have been considered include: (1) a loss-of-coolant accident in the cold leg of the primary loop; (2) loss of primary flow; and (3) loss of power transients for a mixed core containing three UOX and one MMF assemblies in a "colorset". Reactor kinetics was modeled by a point kinetics model with reactivity feedbacks from moderator void, moderator temperature, and fuel temperature (Doppler effect). A large-break loss of coolant accident was analyzed earlier. Three factors rise as key measures of inert matrix loaded core transient behavior; hot pin radial peaking, thermal conductivity, and fuel volumetric heat capacity. A fuel matrix with low thermal conductivity will end up having a higher peak clad temperature during transients (loss of cooling, etc.) due to its inability to transfer heat effectively to the clad-coolant boundary. This causes a higher rise in fuel temperature during the accident progression. Temperature rises higher than that experienced in standard UOX fueled reactor cores may compromise the safety envelope and therefore inert matrix fuel development generally focuses on inert matrix material compositions having thermal conductivity equivalent to or higher than that of UOX matrix fuel. As noted earlier, annular fuel pellets may also be used to reduce the maximum fuel temperature. Other factors such as differences in the reactivity coefficients, kinetics parameters and control worths will have an effect on the progression of the accident (e.g., power profile, effectiveness of scram).

As illustrated above the general neutronic and thermal-hydraulic performance of the candidate IMF compositions does not depend greatly on the thermal conductivity of the matrix. Thermal conductivity does however, play an important role in the transient behavior of the fuel and the thermal conductivities of the proposed compositions vary significantly. Thermal conductivity generally governs the rate at which decay heat is transferred to the clad/coolant boundary and hence affects the rate at which a reactor core cools during a transient scenario. The three accidents analyzed for this paper illustrate the potential impacts of introducing IMF into an LWR. Key results are discussed to demonstrate the influence of performance parameters on the progression and consequences of various accident scenarios.

To illustrate the behavior of the candidate IMF materials, Figure 3 shows a comparison between peak clad temperature (PCT) for the hot pin for a UOX loaded core and the hot pin for the IMF materials in a mixed UOX/IMF core using materials, $\mathrm{ZrO}_{2}-\mathrm{MgO}$ and $\mathrm{SiC}$ under a loss of coolant accident.

In a mixed UOX/IMF core, the relative magnitude of the PCT in the IMF and the UOX hot assembly is a direct consequence of the core power distribution. In the RELAP5 model, the hottest fuel pin shares the same coolant channel with the rest of fuel pins in the hottest fuel assembly. Thus the PCT is a function of both the pin power and the hot assembly power which determines the bulk coolant temperature experienced by the hot pin. According to the result of the "colorset" calculation each UOX 
assembly generates more power than the surrounding IMF assembly. On the other hand the peak fuel pin in the "colorset" is found in the IMF assembly. Thus the hottest fuel pin in the core is located separate from the hottest fuel assembly in the core. The RELAP5 results indicate that the maximum PCT in a loss of coolant accident occurs in the hottest UOX assembly in a mixed core. Because of the lower power in the IMF assembly the PCT for IMF is lower than the corresponding PCT for the UOX assembly.

In comparing the PCT for the UOX fuel in a mixed core and the PCT for the UOX fuel in a standard PWR it is noted that the pin-wise power distribution is more uniform in the fuel assemblies of a standard PWR. This results in the $\mathrm{UO}_{2}$ fuel in a standard PWR having a lower PCT than that for the UOX assembly in a mixed core.

In addition to a loss of coolant accident, two additional transients have been analyzed for the mixed UOX/IMF cores and a standard PWR UOX core. The two transients are loss of power and loss of primary flow. Figure 4 shows the PCT behavior with time under loss of power and loss of primary flow scenarios. A loss of power transient assumes tripping of the primary pumps, the turbine and the main feedwater pumps, followed by a reactor trip. After 75 seconds from the reactor trip only the emergency feedwater pump is assumed to inject emergency feedwater to the four steam generators. The PCT in this transient experienced an initial decrease after the reactor trip followed by a slow increase due to a reduction in heat removal by the steam generators. The upward trend of the PCT was finally mitigated by the injection of emergency feedwater that restored the heat removal capacity of the steam generators.

A loss of primary flow transient was initiated by a trip of the primary pumps at time zero, followed by a reactor trip at $87 \%$ flow. There was about a five-second delay in the reactor trip while the core flow is reduced due to the pump trip. With a decrease in core flow the core coolant temperature began to rise. The negative moderator temperature coefficient then added negative reactivity to the core. This was reflected in a downward drift in core power before the reactor trip shown in Figure 5. It is also of interest to note the responses of the fuel temperature for different fuel compositions. In general a fuel with higher thermal conductivity will have a lower fuel temperature as shown in Figure 6 indicative of its ability to transfer heat to the clad/coolant boundary.

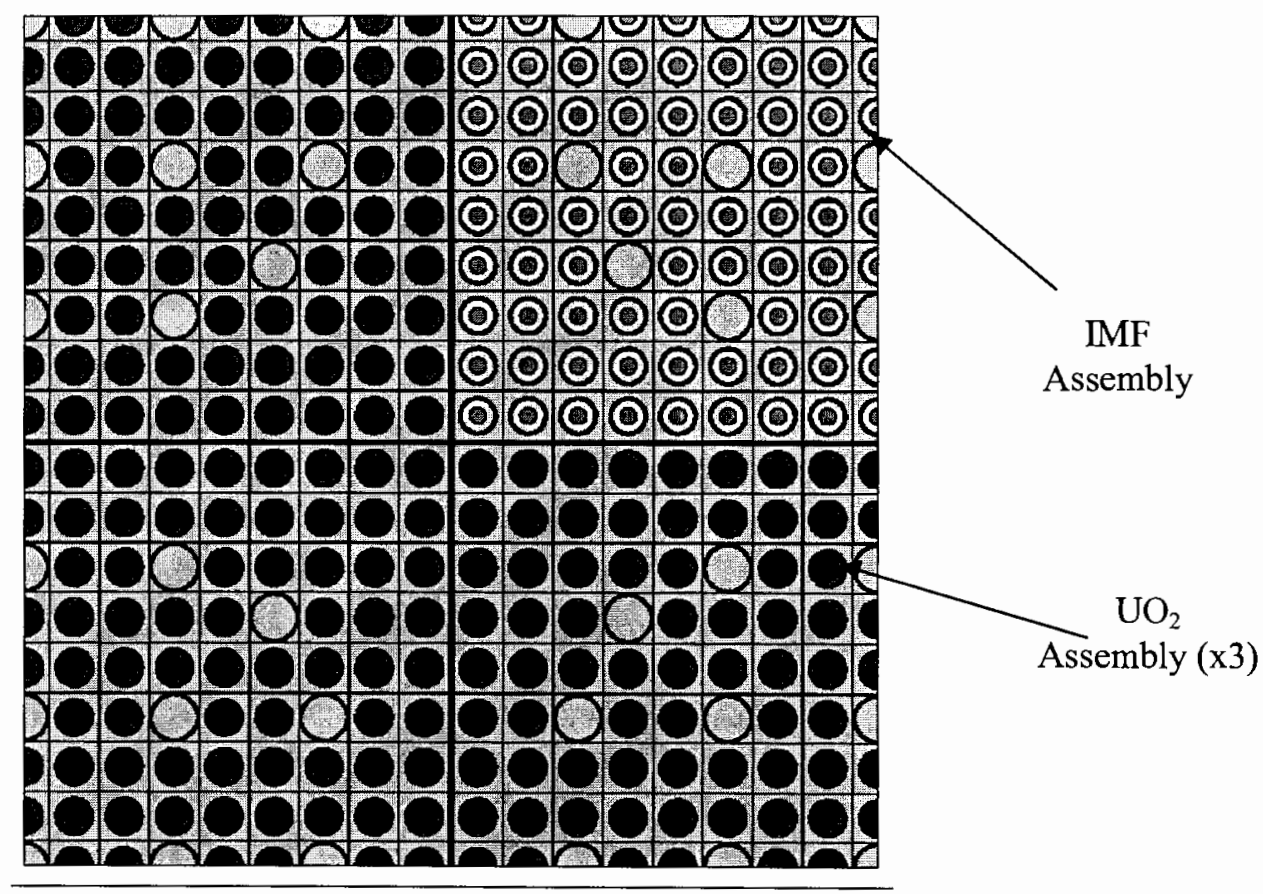


Figure 1. MCNP colorset geometry for (3-UOX/1-IMF) assemblies.

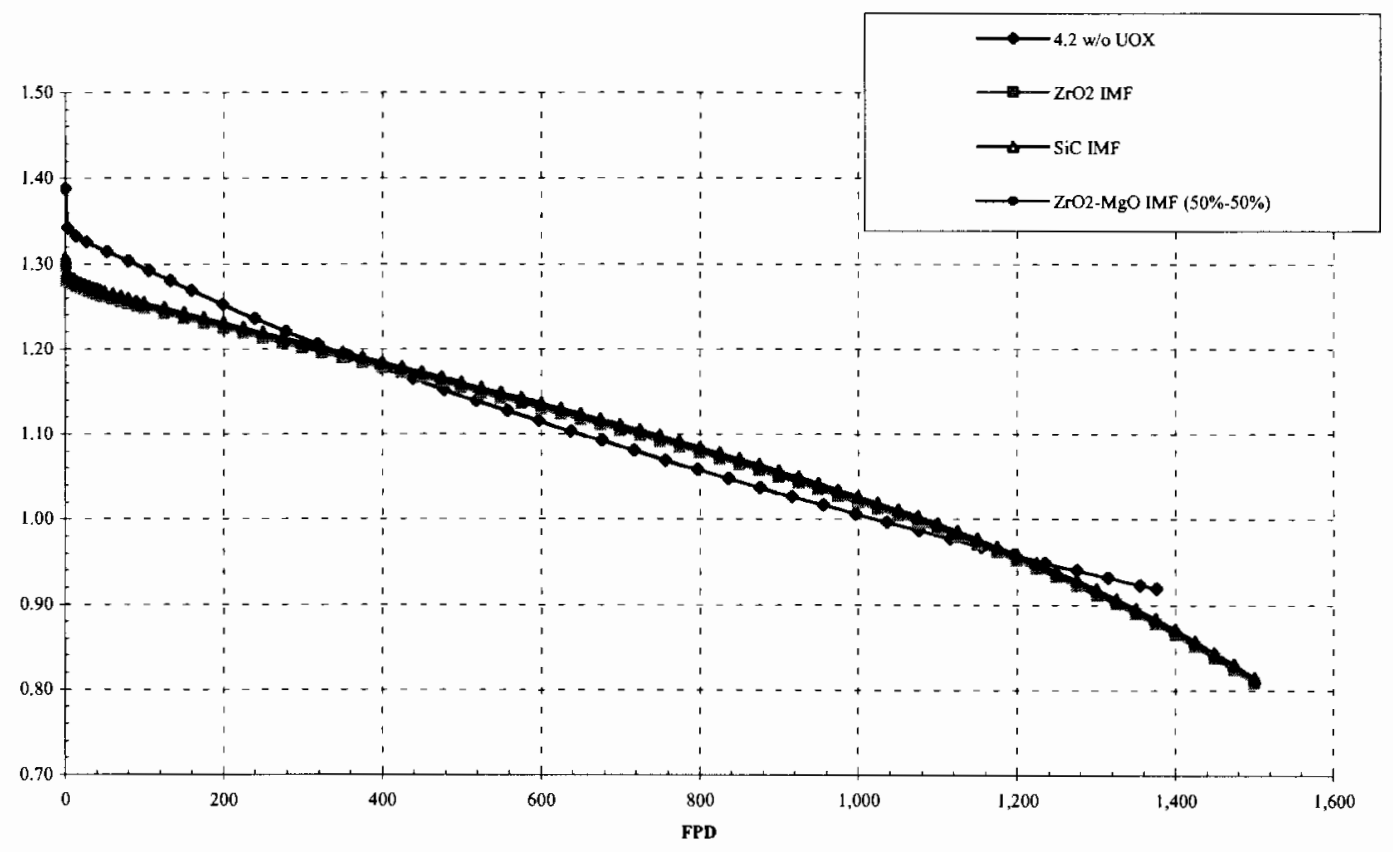

Figure 2. Kinf vs. full power day burnup graph comparison with Np-Pu-Am-MOX and UOX.
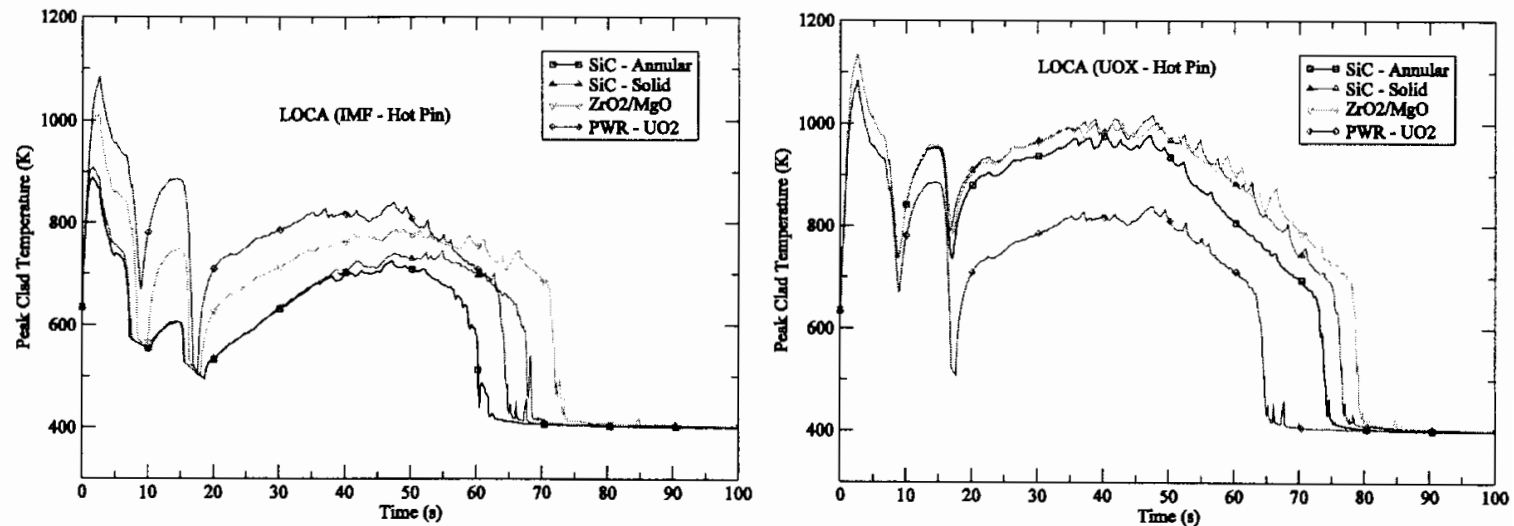

Figure 3. Peak clad temperature for hot pin comparison between $\mathrm{MOX}$ and $\mathrm{ZrO}_{2} / \mathrm{MgO}$ and $\mathrm{SiC}$ inert matrix materials. 

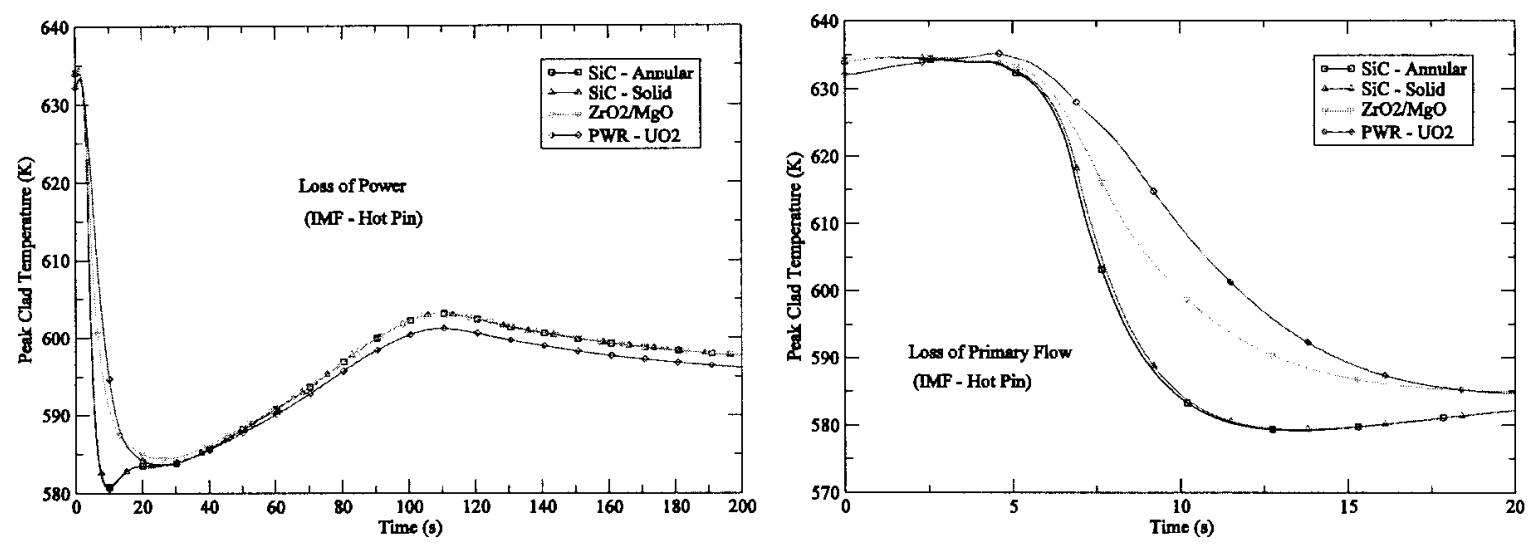

Figure 4. Peak clad temperature for hot pin for Loss of Power and Loss of Primary Flow transient.

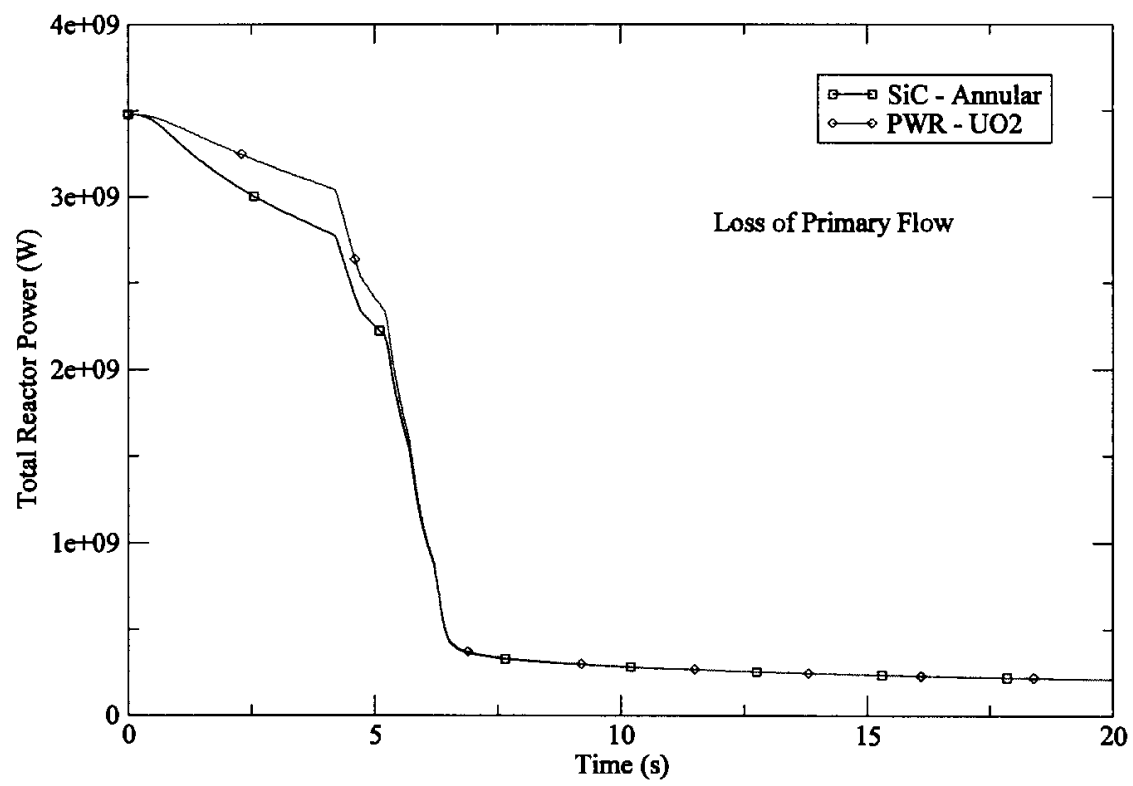

Figure 5. Reactor power under loss of flow transient. 


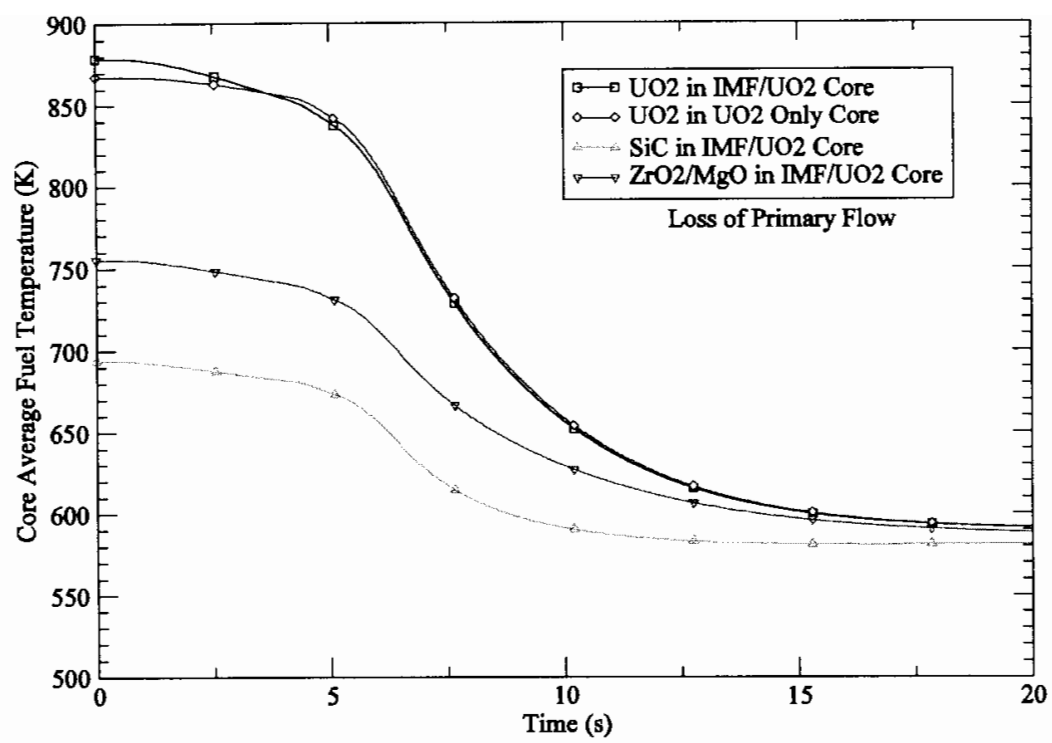

Figure 6. Core average fuel temperature under loss of flow.

The results of the Neutronic Performance Analysis show that there is no significant difference in the system criticality due to the matrix materials considered $\left(\mathrm{ZrO}_{2}, \mathrm{SiC}\right.$, or $\left.\mathrm{MgO}-\mathrm{ZrO}_{2}\right)$ assuming an 18 month operating cycle.

Other matrix materials such as $\mathrm{Zr}$-metal, $\mathrm{ZrO}_{2}-\mathrm{MgO}-\mathrm{CaO}, \mathrm{ZrO}_{2}-\mathrm{CaO}$ are potential candidates for additional consideration if the neutronic behavior is similar to that exhibited by the materials used in this study.

The matrix material composition and fissile loading should be defined basing on thermo-hydraulic analysis (heat flux, DNBR and fuel central-line temperature). The mechanical behavior of the fuel compositions under irradiation must be determined because the discharged accumulated burnup is very high and there is a high volumetric heat source in the fuel.

The choice of matrix materials is affected by whether a once-through or recycle scenario is desired.

The results for the reactivity coefficients and control worths show that the soluble boron worth of IMF is lower (very similar to MOX case) than for UOX standard fuel. In addition, the IMF fuel has significant low Doppler Coefficient. Using a burnable poison based on $\operatorname{Er}_{2} \mathrm{O}_{3}$ resonance absorber to significantly increase the Doppler coefficient will require compensating for the reduction in criticality with increased fissile loadings which may adversely affect other coefficients. Mixed UOX/IMF cores may be required to ensure that the reactor remains within its operational and safety envelope. Full threedimensional simulations of mixed cores must be performed to confirm these results.

Initial transient analysis shows that $\mathrm{ZrO}_{2} \mathrm{MMF}$ fuel has higher peak clad temperature than UOX and $\mathrm{SiC} \mathrm{IMF}$ fuel. The $\mathrm{MgO}-\mathrm{ZrO}_{2}$ thermal conductivity can be adjusted by varying the $\mathrm{MgO} / \mathrm{ZrO}_{2}$ ratio and measurements indicate that the achievable thermal conductivity is higher than the five $\mathrm{W} / \mathrm{m}-\mathrm{K}$ used in the calculations for this study. Initial analysis indicates that a $50 / 50 \mathrm{wt} \%$ mixture of $\mathrm{MgO}-\mathrm{ZrO} 2$ results in peak clad temperatures similar to UOX. 


\section{FUEL SYSTEM FABRICATION DEVELOPMENT \\ 4.1 MOX-Minor Actinide Fuel Development}

Mixed oxide fuel compositions have been developed and utilized in operating nuclear power plants around the world for several years. In fact the United States plans on destruction and utilization of approximately $30 \mathrm{MT}$ of weapons grade plutonium in MOX fuel assemblies in Catawba-1 Nuclear Power Plant beginning in 2005 or 2006. The history and data available for MOX fuel compositions makes it a logical choice for burning of $\mathrm{Pu}$ in LWR power systems. A logical extension of the traditional MOX fuel composition would be to test the effect under irradiation, the addition of Americium and Neptunium oxide to the fuel composition. For destruction of the minor actinides, the United States plans on testing traditional reactor grade MOX fuel containing additions of Americium and Neptunium oxide at quantities expect in recycled LWR spent nuclear fuel.

\subsection{SiC Inert Matrix Development}

Most of the work summarized in Section 4.2 can be found in the following reference:

R.A. Verral, et al., "CANDU ${ }^{\circledR}$ Inert Matrix Fuel", Proc. LAEA Tech. Comm. Mtg. on Fuel Cycle Options for LWRs and HWRs, Victoria, Canada, 1998.

\subsubsection{Fabrication Development}

$\mathrm{SiC}$ is a covalently bonded material and as such is very difficult to sinter. High $\left(>2000^{\circ} \mathrm{C}\right)$ temperature and pressure and/or the use of sintering aids are normally required to achieve high densities. This is a radical departure from the sintering of $\mathrm{UO}_{2}$ and $\mathrm{MOX}$ fuel, which is achieved by pressure-less sintering at $1600-1700^{\circ} \mathrm{C}$. This was seen as an impediment to the acceptance of $\mathrm{SiC}$ as a candidate for an inert matrix fuel. A contract was arranged between AECL and Queen's University to investigate methods of reducing the sintering temperature and pressure to a range comparable to $\mathrm{UO}_{2}$ sintering. An extensive investigation was undertaken over several years. Several sintering additives were investigated and $\mathrm{CeO}$ was used as a plutonium oxide surrogate. The work culminated with high-density pellets produced by pressure-less sintering at temperatures of $\approx 1700^{\circ} \mathrm{C}$. The pellets were made by blending the following wt $\%$ of $\mathrm{SiC}$ and additives together: $74.4 \% \mathrm{SiC}, 10.0 \% \mathrm{CeO}_{2}, 8.4 \% \mathrm{Al}_{2} \mathrm{O}_{3}$ and $7.2 \% \mathrm{Y}_{2} \mathrm{O}_{3}$. This represents approximately 18 volume \% additives. Attempts to reproduce these results at CRL have been successful but require slightly higher sintering temperatures, $\approx 1850^{\circ} \mathrm{C}$. At these higher sintering temperatures, highdensity pellets have been produced with less additives $\left(80.9 \% \mathrm{SiC}, 5.0 \% \mathrm{CeO}_{2}, 6.9 \% \mathrm{Al}_{2} \mathrm{O}_{3}\right.$, and $7.2 \%$ $\mathrm{Y}_{2} \mathrm{O}_{3}$ ).

Characterization suggests the pellets are made up of a pure $\mathrm{SiC}$ matrix with at least one other phase produced by a reaction between the additives. $\mathrm{X}$-ray analysis clearly identifies $\beta$-SiC, garnet $\left(3 \mathrm{Y}_{2} \mathrm{O}_{3} \cdot 5 \mathrm{Al}_{2} \mathrm{O}_{3}\right)$ and $\alpha$-SiC. Some peaks were unidentified and may correspond to another oxide phase containing the $\mathrm{Ce}$ in some combination with the $\mathrm{Y}$ and/or $\mathrm{Al}$.

AECL's current plan is to use highly enriched uranium (HEU, $\approx 4 \% \mathrm{U}-235$ ) instead of plutonium in the initial irradiations. The use of HEU will achieve virtually the same results as $\mathrm{Pu}$ while making fabrication considerably easier (glove boxes not required). To this end, high-density pellets have been fabricated with natural $\mathrm{UO}_{2}$. 


\subsubsection{Material Compatibility}

Samples of SiC containing the sintering-aid additives were tested for compatibility with coolant, ground water (for waste management) and Zircaloy 4 (cladding). Tests for coolant interaction were carried out under typical CANDU ${ }^{\circledR}$ coolant conditions of $300^{\circ} \mathrm{C}$ and $\mathrm{pH} 10.3$ (via LiOH addition). Interaction with coolant under these conditions was negligible. Attack by groundwater, under what are considered to be "extreme" conditions, was simulated by exposing a sample to acidic water (pH 2.9) at $96^{\circ} \mathrm{C}$. Following $119 \mathrm{~h}$ of exposure, ppm quantities of additives and Si could be detected. The conclusion was that these dissolution rates would not be a problem for $\mathrm{SiC}$ as a waste form.

Compatibility with $\mathrm{Zr}-4$ was tested by heating polished $\mathrm{SiC}$ and $\mathrm{Zr}-4$ samples held together under light pressure. Samples were heated to $1000^{\circ} \mathrm{C}, 1500^{\circ} \mathrm{C}$ and $1700^{\circ} \mathrm{C}$ in an argon atmosphere. The results were as follows:

- $\quad 1000^{\circ} \mathrm{C}, 1$ hour - no interaction

- $\quad 1500^{\circ} \mathrm{C}, 1$ hour - reaction to form $\mathrm{ZrC}$ and free Si. Free Si forms low melting temp eutectic with $\mathrm{Zr}-4$

- $\quad 1700^{\circ} \mathrm{C}, 15$ minutes - Similar to above but more pronounced.

\subsubsection{Reactor Physics}

Simulations with a plutonium-only SiC-IMF and a plutonium-plus-actinides SiC-IMF were carried out. For both cases the standard 37 -element bundle was used. The plutonium or plutonium plus actinides were added to the outer two rings of elements while the central seven pins contained gadolinium. This burnable poison was added to suppress initial reactivity, reduce the refueling power ripple and give the bundle a negative void reactivity.

With the plutonium only case, each bundle would contain $250 \mathrm{~g}$ of $\mathrm{Pu}$ and at the calculated refueling rate of 15 bundles per day, approximately one tonne of plutonium could be annihilated per $\mathrm{CANDU}^{\circledR}$ unit, per year ( $80 \%$ capacity factor and $94 \%$ of fissile Pu destroyed). Bundle and Channel power are within current licensing limits.

In the plutonium-plus-actinides simulation, $356 \mathrm{~g}$ of Pu plus $44 \mathrm{~g}$ of a neptunium, americium and curium mixture are present in the fresh fuel. Sixty percent of the actinides and $90 \%$ of the plutonium are destroyed. In this simulation approximately $70 \mathrm{~kg}$ of actinides and $860 \mathrm{~kg}$ of $\mathrm{Pu}$ are destroyed per $\mathrm{CANDU}^{\circledR}$ unit per year.

\subsubsection{Fission Fragment Damage}

$\mathrm{SiC}$ is expected to have adequate resistance to structural damage due to neutrons but another route via which damage can occur is fission fragments. In order to simulate fission-fragment damage the SiCIMF along with several other potential IMF candidate materials were bombarded with high-energy $(72 \mathrm{MeV})$ iodine ions. Polished specimens were exposed to a 3-mm diameter beam produced by an accelerator at temperatures ranging between room and $1200^{\circ} \mathrm{C}$. The maximum dose applied was equivalent to typical CANDU ${ }^{(8)}$ six burnups. Following exposure, profilometry was performed to detect any relief in the polished surface. Only Zirconia, $\mathrm{SiC}$ and $\mathrm{UO}_{2}$ showed no sign of relief under all of the test conditions. This result supports, but does not prove, that the SiC-IMF will be stable in reactor. 


\subsection{Dual Phase ${\mathrm{MgO}-\mathrm{ZrO}_{2}}_{2}$ Inert Matrix Development}

$\mathrm{MgO}-\mathrm{ZrO}_{2}-\mathrm{PuO}_{2}$ ceramic composites are being studied as an $\mathrm{MF}$ form for LWRs. The motivation of this work is to develop an IMF with a thermal conductivity superior to that of the fuels based on yttria stabilized zirconia. The concept uses the $\mathrm{MgO}$ phase as an efficient heat conductor to increase thermal conductivity of the composite. In this paper ceramic fabrication and characterization by scanning electron microscopy, energy and wavelength dispersive $\mathrm{X}$-ray spectroscopy is discussed. Characterization shows that the ceramics consist of the two-phase matrix and $\mathrm{PuO}_{2}$-rich inclusions. The matrix is comprised of pure $\mathrm{MgO}$ phase and $\mathrm{MgO}-\mathrm{ZrO}_{2}-\mathrm{PuO}_{2}$ solid solution. The $\mathrm{PuO}_{2}$-rich inclusion contained dissolved $\mathrm{MgO}$ and $\mathrm{ZrO}_{2}$.

\subsubsection{Introduction}

Advanced fuel cycle initiative is being pursued by the United States Department of Energy with a four-prong objective: (1) recovery of energy from SNF, (2) reduction of the inventory of civilian plutonium, (3) reduction of the toxicity and heat load of stored SNF, and (4) more effective use of the SNF repository. The advanced fuel cycle initiative mission is to develop and demonstrate technologies that enable the transition to a stable, long-term, environmentally, economically, and politically acceptable fuel cycle.

Use of existing LWRs as a neutron source to fission plutonium and transmute minor actinides provides a near-term opportunity for very effective in-reactor disposition of these surplus nuclear materials 0 . A need for a non-fertile matrix material that can be safely used in LWR fuels as plutonium and minor actinide dilutant drives material development research in this field.

Yttria stabilized zirconia (YSZ) is the most evolved candidate for use in IMF. Both steady-state 0 and transient 0 irradiations of YSZ-based IMF have been performed. Material properties of YSZ have been closely examined 0,0 . Out-of-pile irradiation studies designed to understand the mechanism of radiation damage have been completed0. Neutronic feasibility of YSZ-based IMF has been also assessed 0 complemented by core burnup calculations and accident analyses 0 . Despite its excellent radiation resistance, compatibility with reactor materials and good neutronic properties, very low thermal conductivity is the main disadvantage of YSZ. According to a recent analysis 0 fuel centerline temperature of the YSZ-based $\mathrm{IMF}$ may be $100^{\circ} \mathrm{C}$ higher than the limit specified for LWRs. Safe use of YSZ as a matrix in LWR fuel is only possible if a reactor is operated at a lower power or if fuel pellets feature central voids. Both measures increase the cost and decrease the feasibility of plutonium disposition.

Use of composites containing a phase with a higher thermal conductivity could improve performance characteristics of zirconia-based IMF. Use of $\mathrm{MgO}$ as such a phase has been proposed 0,0 . It has been shown 0 that dual-phase $\mathrm{MgO}-\mathrm{ZrO}_{2}$ ceramics have the thermal conductivity superior to that of $\mathrm{UO}_{2}$ and have notable resistance to the water at the temperature of $300^{\circ} \mathrm{C}$ and pressure $8.6 \mathrm{MPa}$, making them attractive for use as an $\mathrm{IMF}$ matrix. Development of $\mathrm{MMF}$ based on $\mathrm{MgO}-\mathrm{ZrO}_{2}$ ceramics continues at Idaho National Laboratory with the support of the AFCI. The present paper describes results of the first experiment to fabricate and characterize $\mathrm{MgO}-\mathrm{ZrO}_{2}-\mathrm{PuO}_{2}$ ceramics as a potential $\mathrm{IMF}$ form for use in LWRs.

\subsubsection{Fabrication}

$\mathrm{MgO}-\mathrm{ZrO}_{2}-\mathrm{PuO}_{2}$ ceramics were fabricated from the oxide powder mixture using conventional pressing and sintering techniques. The fabrication process was based on the earlier work 0 that dealt with non-radioactive materials. The flow diagram of the fabrication process is shown in Figure 7. 
Pre-weighed amounts of magnesia and magnesium zirconium oxide powders were combined with water in a beaker. The weight of water was approximately three times greater than the weight of the powders combined. The water and powder mixture was stirred using a magnetic stirring bar for six hours. The slurry was dried in air at $80^{\circ} \mathrm{C}$ for five hours. The resulting powder was transferred into an alumina crucible and heat-treated at $1000^{\circ} \mathrm{C}$ for five hours in a high temperature tube furnace. The ramp-up and ramp-down rates were $10^{\circ} \mathrm{C}$ per minute. Upon cool-down, zinc stearate (Fisher Scientific Fair Lawn, NJ Z-78-4, lot 871095 , UPS grade) in the amount of $1 \%$ by weight was mixed into the powder using a mortar and a pestle. The powder was then pressed into pellets with a force of $13.34 \mathrm{kN}$ using a cylindrical die of $12.72-\mathrm{mm}$ diameter. Resulting $\mathrm{MgO}-\mathrm{ZrO}_{2}$ pellets weighing $3.8986 \mathrm{~g}$ and $3.3571 \mathrm{~g}$ were transferred into a glovebox. Once in the glovebox, the pellets were ground and $1.0265 \mathrm{~g}$ of $\mathrm{PuO}_{2}$ powder was mixed in using a mortar and pestle. The powder was then pressed into pellets with a force of $44.45 \mathrm{kN}$ using a cylindrical die of 12.72-mm diameter. Resulting pellets were ground into powder using a mortar and pestle. The powder was passed through a sieve with an aperture size of 250 microns. The mixture was pressed again into pellets with a force of $13.34 \mathrm{kN}$ using a cylindrical die of $12.72-\mathrm{mm}$ diameter. The pellets were placed into an alumina crucible and sintered in air for 7.5 hours at $1700^{\circ} \mathrm{C}$ in a high temperature box furnace. The ramp-up rate was $10^{\circ} \mathrm{C}$ per minute up to $1000^{\circ} \mathrm{C}$ and $5^{\circ} \mathrm{C}$ per minute from $1000^{\circ} \mathrm{C}$ to $1700^{\circ} \mathrm{C}$. The ramp-down rate was $10^{\circ} \mathrm{C}$ per minute. The pellets were cooled in the furnace after sintering.

Magnesium oxide was procured from Cerac Incorporated (Milwaukee, WI, item M-1017, lot X25111, typically $99.95 \%$ pure). Magnesium zirconium oxide supplied by Alfa Aesar (Ward Hill, minor actinides, stock 12343, lot C01E, $99.7 \%$ metals basis) was used as a source of zirconia. Use of magnesium zirconium oxide facilitated obtaining a homogeneous distribution of $\mathrm{MgO}$ and $\mathrm{ZrO}_{2}$ in the final product.

\subsubsection{Characterization of $\mathrm{MgO}-\mathrm{ZrO} 2-\mathrm{PuO}_{2}$ ceramics}

4.3.3.1 Visual inspection, dimensions, weight and density. Two ceramic pellets were fabricated. Photographs of the pellets are shown in Figure 8. As-sintered pellets are shown in Figure 8a. Pellet cross-section exposed by cutting a pellet with a diamond saw is shown in Figure $8 \mathrm{~b}$. Each pellet featured one crack near one face as illustrated in Figure 8c.

The pellets were weighed and measured with a caliper. Results of the measurements are shown in Table 4. Pellet diameter was measured three times: in the mid-pellet and near each face. Pellet hourglassing developed during sintering was manifested by diameter decrease in the mid-pellet region.

Pellet density values derived from weight and volume and measured by water immersion technique are included in Table 4 . The pellet density was significantly lower than that of $\mathrm{MgO}-\mathrm{ZrO}_{2}$ ceramics studied in the earlier work $0 . \mathrm{MgO}^{-} \mathrm{ZrO}_{2}$ ceramics containing $50 \mathrm{wt} \%$ of $\mathrm{MgO}$ had the density of 4.39 $\mathrm{g} / \mathrm{cm}^{3}$ measured by water immersion.

4.3.3.2 Scanning Electron Microscopy. Scanning electron microscopy (Zeiss DSM960A digital scanning electron microscope), energy and wavelength dispersive x-ray analyses (Oxford Instruments, Freemont, CA) were carried out with an objective to identify the phases present in the ceramics and to determine chemical composition of each phase. Previous fabrication and characterization studies 0 established that $\mathrm{MgO}-\mathrm{ZrO}_{2}$ and $\mathrm{MgO}-\mathrm{ZrO}_{2}-\mathrm{Er}_{2} \mathrm{O}_{3}$ systems containing from 40 to $70 \mathrm{wt} \%$ of $\mathrm{ZrO}_{2}$ and 7 $\mathrm{wt} \% \mathrm{Er}_{2} \mathrm{O}_{3}$ sintered in air at $1700^{\circ} \mathrm{C}$ consisted of two phases: zirconia-based cubic solid solution and pure cubic magnesia. The amount of magnesia dissolved in the zirconia-based cubic solid solution phase was 13-17 mol\%. Erbia dopant preferentially dissolved in the zirconia phase. Presence of pure MgO phase in the ceramics had a positive effect on their thermal conductivity. The same effect is desired in the MgO- 
$\mathrm{ZrO}_{2}-\mathrm{PuO}_{2}$ system. Thus, understanding the behavior of $\mathrm{PuO}_{2}$ dopant in the $\mathrm{MgO}-\mathrm{ZrO}_{2}$ system is of particular importance.

To produce a sample for the scanning electron microscopy (SEM) the pellet was cut with a diamond saw yielding a disk approximately $2 \mathrm{~mm}$ thick. The disk was broken up to produce smaller fragments by tapping with a pestle. One of the resulting fragments was mounted in the epoxy and manually polished with the silicon carbide paper of 600,800 , and 1200 grit. The polishing time was kept to a minimum in order to reduce the personnel radiation exposure. The sample submitted for analysis is shown in Figure 9.

Figure 10 shows key microstructural features identified in the sample: a two-phase matrix

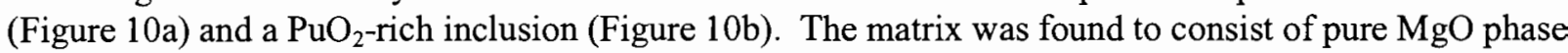
(dark phase in Figure 10a) and $\mathrm{MgO}-\mathrm{ZrO}_{2}-\mathrm{PuO}_{2}$ solid solution (light phase in Figure 10a). Except for the greater porosity, the microstructure of the matrix was found to be virtually identical to that observed in $\mathrm{MgO}-\mathrm{ZrO}_{2}$ and $\mathrm{MgO}-\mathrm{ZrO}_{2}-\mathrm{Er}_{2} \mathrm{O}_{3}$ systems 0 . The $\mathrm{PuO}_{2}$-rich inclusion shown in Figure $10 \mathrm{~b}$ contained $\mathrm{MgO}$ and $\mathrm{ZrO}_{2}$ with $\mathrm{PuO}_{2}$ being a dominant component. The columnar grains surrounding the $\mathrm{PuO}_{2}$-rich inclusion were believed to be formed due to significant variation of $\mathrm{ZrO}_{2}$ solubility in $\mathrm{PuO}_{2}$ with temperature. Examination of the $\mathrm{PuO}_{2}$-rich end of the $\mathrm{PuO}_{2}-\mathrm{ZrO}_{2}$ phase diagram 0 revealed that the solubility of $\mathrm{ZrO}_{2}$ in $\mathrm{PuO}_{2}$ increases from 20 to $60 \mathrm{~mol} \%$ with the increase of temperature from $1200^{\circ} \mathrm{C}$ to $1700^{\circ} \mathrm{C}$. Therefore, this variation in solubility caused diffusion of $\mathrm{ZrO}_{2}$ into the $\mathrm{PuO}_{2}$ particle during the furnace ramp-up and sintering, and rejection of $\mathrm{ZrO}_{2}$ by $\mathrm{PuO}_{2}$-rich particle during furnace ramp-down. Rejection of $\mathrm{ZrO}_{2}$ by the $\mathrm{PuO}_{2}$-rich particle caused particle densification which led to the formation of a gap between the particle and the matrix observed in Figure 10b.

Energy Dispersive X-ray Spectroscopy (EDS) was used to determine chemical composition of the phases present in the ceramics. Typical EDS spectra are shown in Figure 11. As evident from Figure 11, the matrix $\mathrm{Pu}$ content is higher in the vicinity of $\mathrm{PuO}_{2}$-rich inclusions. This observation suggests that the solubility limit of $\mathrm{PuO}_{2}$ in the matrix locations away from the inclusions was not reached. Thus, observed undesirable inhomogeneity is possibly due to inadequate mixing rather than the limited solubility of $\mathrm{PuO}_{2}$ in the matrix.

Detailed EDS results are shown in Table 5. EDS spectra were taken in 15 locations in $\mathrm{MgO}-\mathrm{ZrO}_{2}-$ $\mathrm{PuO}_{2}$ grains, 10 locations in $\mathrm{MgO}$ grains, and 5 locations in a $\mathrm{PuO}_{2}$-rich inclusion. Thus, the numbers in Table 5 are the averages and the standard deviations of these multiple measurements. It should be noted that our EDS system is not capable of quantifying the Pu content. As follows from Table 5, very small amounts of $\mathrm{ZrO}_{2}$ were detected in the $\mathrm{MgO}$ grains. This fact was attributed to the presence of $\mathrm{ZrO}_{2}$ in the neighboring $\mathrm{MgO}-\mathrm{ZrO}_{2}-\mathrm{PuO}_{2}$ grains and possibly to the contamination of the surface of the $\mathrm{MgO}$ grains during polishing. Absence of dissolved $\mathrm{ZrO}_{2}$ and $\mathrm{PuO}_{2}$ in $\mathrm{MgO}$ was additionally confirmed by wavelength dispersive spectroscopy.

\subsubsection{Conclusions}

$\mathrm{MgO}-\mathrm{ZrO}_{2}-\mathrm{PuO}_{2}$ ceramics were fabricated and characterized by SEM, EDS, and wavelength dispersive spectroscopy. Ceramics were found to consist of the two-phase matrix and $\mathrm{PuO}_{2}$-rich inclusions. The matrix was comprised of pure $\mathrm{MgO}$ phase and $\mathrm{MgO}-\mathrm{ZrO}_{2}-\mathrm{PuO}_{2}$ solid solution. The $\mathrm{PuO}_{2}$-rich inclusion contained dissolved $\mathrm{MgO}$ and $\mathrm{ZrO}_{2}$. Based on the characterization work it was concluded that the fabrication process must be modified to achieve homogeneity of the product, reduce porosity, and produce an acceptable fuel form. Improved mixing and calcination of $\mathrm{PuO}_{2}$ powder together with $\mathrm{MgO}$ and $\mathrm{ZrO}_{2}$ will be utilized during fabrication of the next batch of the ceramics. 
The results of this study provide valuable insight on the phase relations in the $\mathrm{MgO}-\mathrm{ZrO}_{2}-\mathrm{PuO}_{2}$ system. The study established that neither $\mathrm{PuO}_{2}$ nor $\mathrm{ZrO}_{2}$ dissolved in the highly thermally conductive $\mathrm{MgO}$ phase. By remaining free from dissolved species, the $\mathrm{MgO}$ phase is expected to maintain its high thermal conductivity acting as efficient means of increasing the thermal conductivity of the entire ceramic composite.

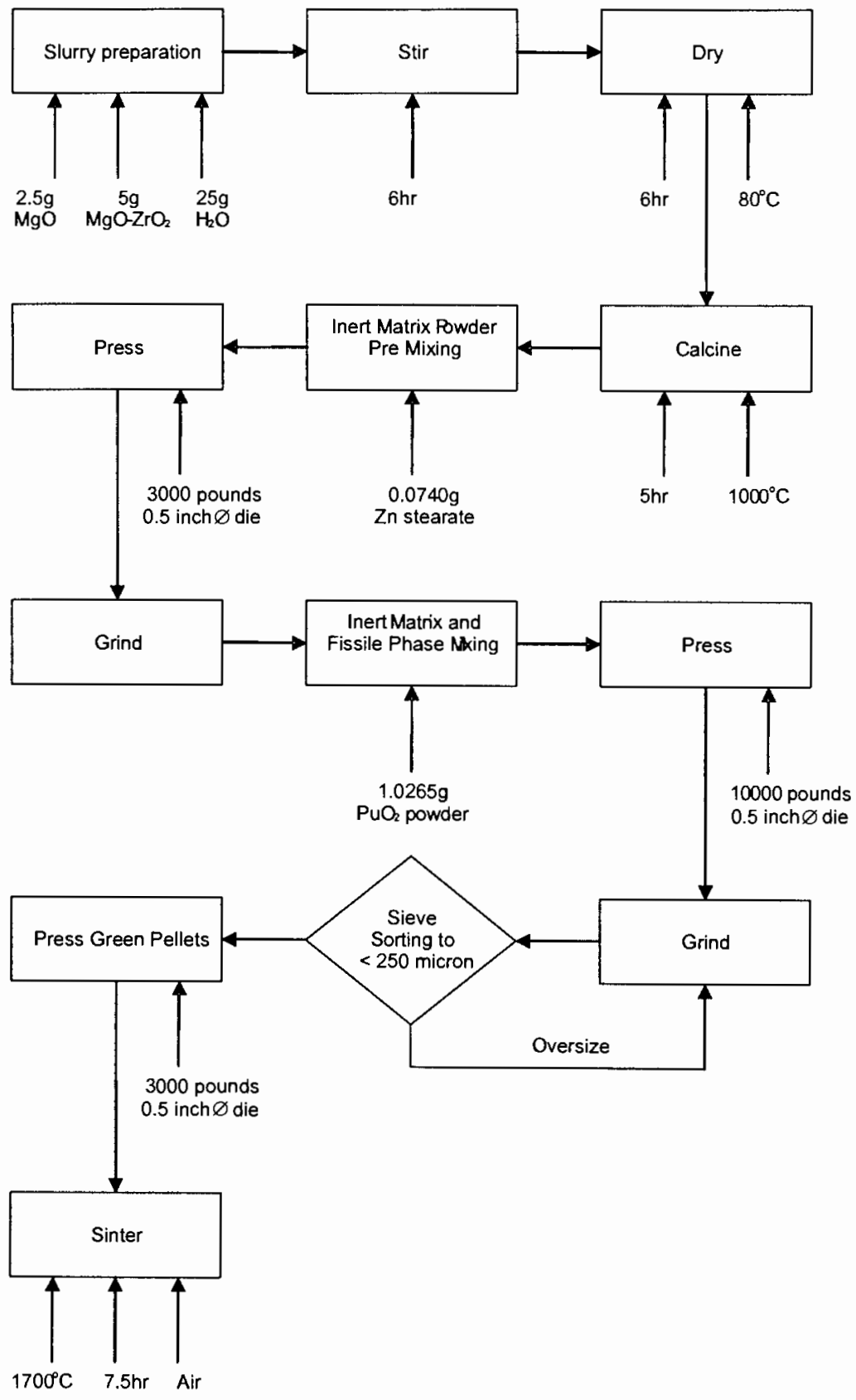

Figure 7. Flow diagram for fabrication of $\mathrm{MgO}-\mathrm{ZrO}_{2}-\mathrm{PuO}_{2}$ ceramics. 


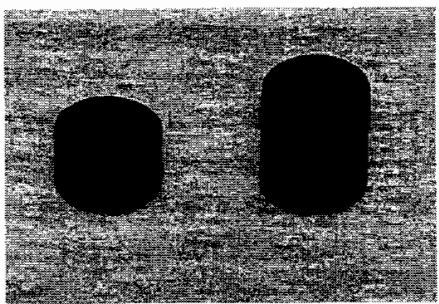

(a)

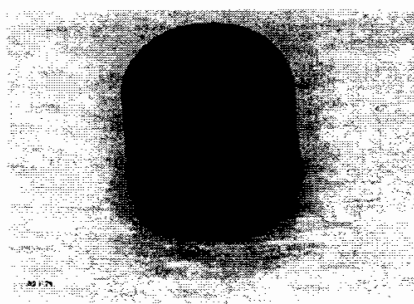

(b)

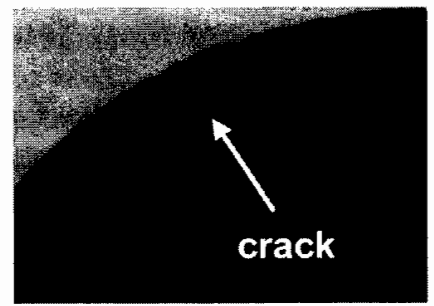

(c)

Figure 8. Fabricated MgO-ZrO2-PuO2 ceramic pellets. (a) as-sintered pellets, (b) pellet cross-section, (c) crack near the face of the pellet.

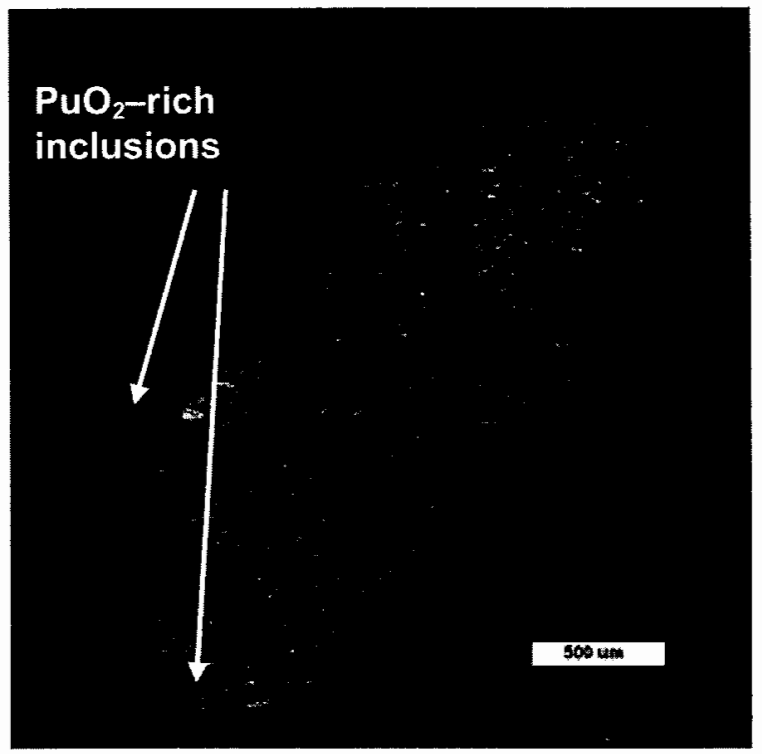

Figure 9. SEM image of the $\mathrm{MgO}-\mathrm{ZrO}_{2}-\mathrm{PuO}_{2}$ ceramic sample submitted for analysis. The black area surrounding and black shapes within the sample are the mounting epoxy. The sample consists of a matrix and $\mathrm{PuO}_{2}$-rich inclusions. 


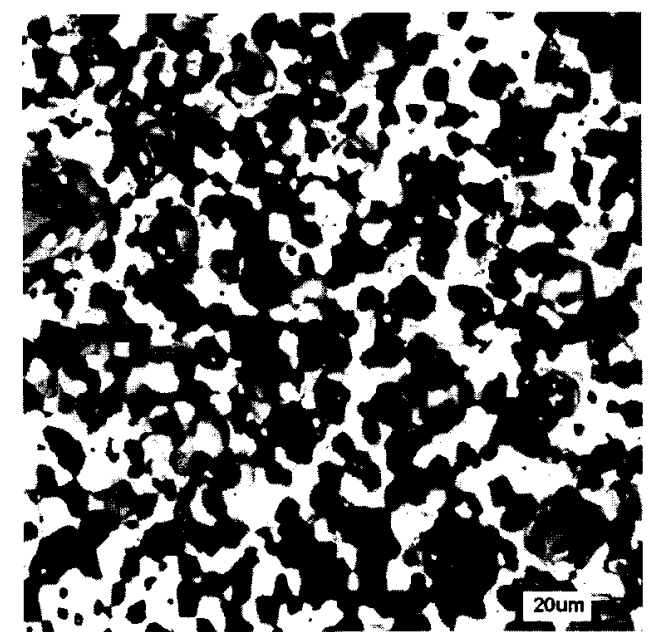

(a)

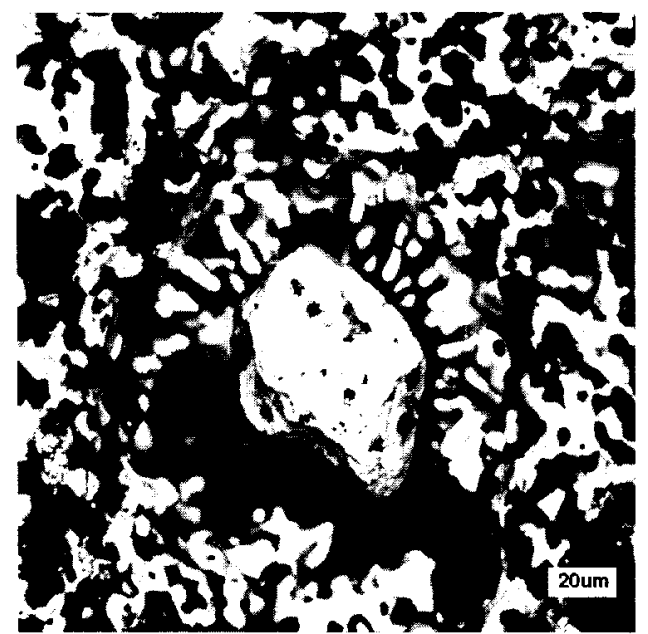

(b)

Figure 10. Key microstructural features identified in the sample are a two-phase matrix (a) and a $\mathrm{PuO}_{2}$ rich inclusion (b). The matrix consisted of pure $\mathrm{MgO}$ phase (dark phase) and $\mathrm{MgO}-\mathrm{ZrO}_{2}-\mathrm{PuO}_{2}$ solid solution (light phase). The $\mathrm{PuO}_{2}$-rich inclusion contained $\mathrm{MgO}$ and $\mathrm{ZrO}_{2}$ with $\mathrm{PuO}_{2}$ being a dominant component.
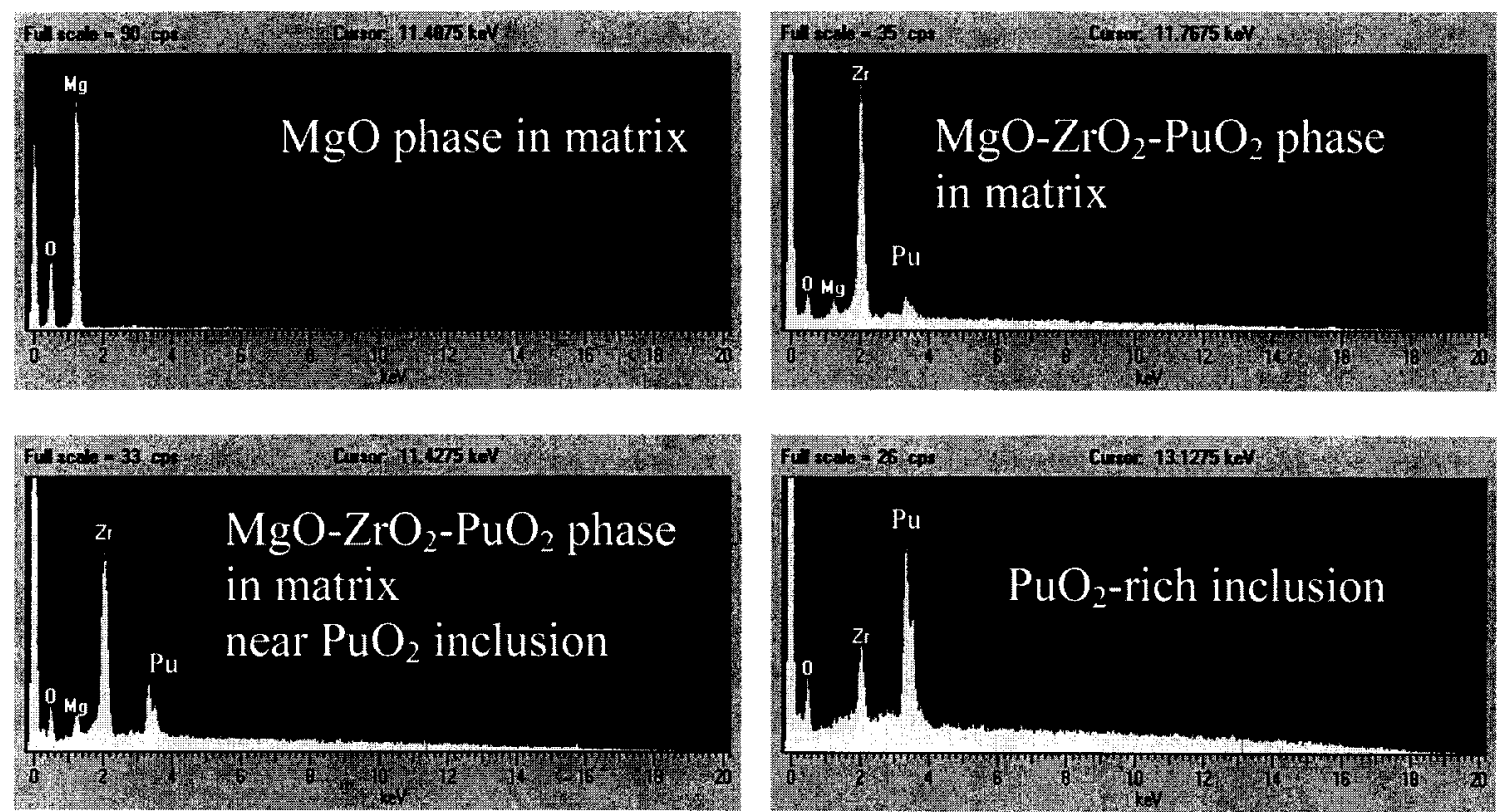

Figure 11. Typical EDS spectra observed in various locations in the ceramic. 
Table 4. Dimensions and weight of the sintered $\mathrm{MgO}-\mathrm{ZrO}_{2}-\mathrm{PuO}_{2}$ ceramic pellets.

\begin{tabular}{|c|c|c|c|c|c|c|c|c|}
\hline \multirow[b]{2}{*}{ Pellet } & \multirow[b]{2}{*}{ Weight, $\mathrm{g}$} & \multirow[b]{2}{*}{ Length, mm } & \multicolumn{4}{|c|}{ Diameter, $\mathrm{mm}$} & \multicolumn{2}{|c|}{ Density, $\mathrm{g} / \mathrm{cm}^{3}$} \\
\hline & & & face & mid-pellet & face & average & bulk & immersion \\
\hline 1 & 5.0406 & 13.00 & 11.59 & 11.40 & 11.60 & 11.53 & 3.71 & 3.8157 \\
\hline 2 & 2.9043 & 7.48 & 11.57 & 11.42 & 11.55 & 11.51 & 3.73 & 3.8751 \\
\hline
\end{tabular}

Table 5. Results from SEM EDS semi-quantitative analysis. Note that the ISIS EDS system cannot perform quantitative analysis for elements heavier than uranium.

\begin{tabular}{|l|l|l|l|l|}
\hline \multicolumn{1}{|c|}{ Phase } & $\mathrm{Mg}$ (atomic\%) & $\mathrm{Zr}$ (atomic\%) & $\mathrm{O}$ (atomic\%) & $\mathrm{Zr}$ to $\mathrm{Mg}$ ratio \\
\hline $\mathrm{MgO}$ grains in matrix & $48.29 \pm 0.92$ & $0.06 \pm 0.04$ & $51.65 \pm 0.94$ & \\
\hline $\mathrm{MgO}_{-} \mathrm{ZrO}_{2}-\mathrm{PuO}_{2}$ grains in matrix & $3.68 \pm 0.37$ & $23.19 \pm 1.10$ & $73.13 \pm 1.00$ & $6.38 \pm 0.83$ \\
\hline $\mathrm{PuO}_{2}$-rich inclusion & $0.91 \pm 0.32$ & $9.66 \pm 0.64$ & $89.43 \pm 0.87$ & $12.63 \pm 5.81$ \\
\hline
\end{tabular}

\subsection{Advanced Pyrochlore Inert Matrix Development}

As discussed above, recent studies on $\mathrm{MgO}-\mathrm{ZrO}_{2}$ composites have shown promising results as potential IMF. $\mathrm{ZrO}_{2}$ has a fluorite structure (where $\mathrm{Zr}$ is in an eightfold coordination environment with oxygen, and oxygen is in a fourfold coordination environment with zirconium). Therefore, from the point of view of crystal chemistry a natural step forward in the development of oxides for IMF is the study of $\mathrm{MgO}$-oxide pyrochlore composites. Oxide pyrochlores are typically ternary compounds of general formula $\mathrm{A}_{2} \mathrm{~B}_{2} \mathrm{O}_{7}$ (where $A$ and $B$ are metallic cations). The relationship between the fluorite and pyrochlore structures is schematically shown in Figure 12. The pyrochlore crystal structure is an aniondeficient fluorite superstructure, where the unit cell is doubled and the original eightfold coordinated Asite is split into A- and B-sites, eightfold and sixfold coordinated, respectively. As a result of the site split and change in coordination environment, the effective stoichiometry of the pyrochlore is oxygen deficient when compared with that of the fluorite.
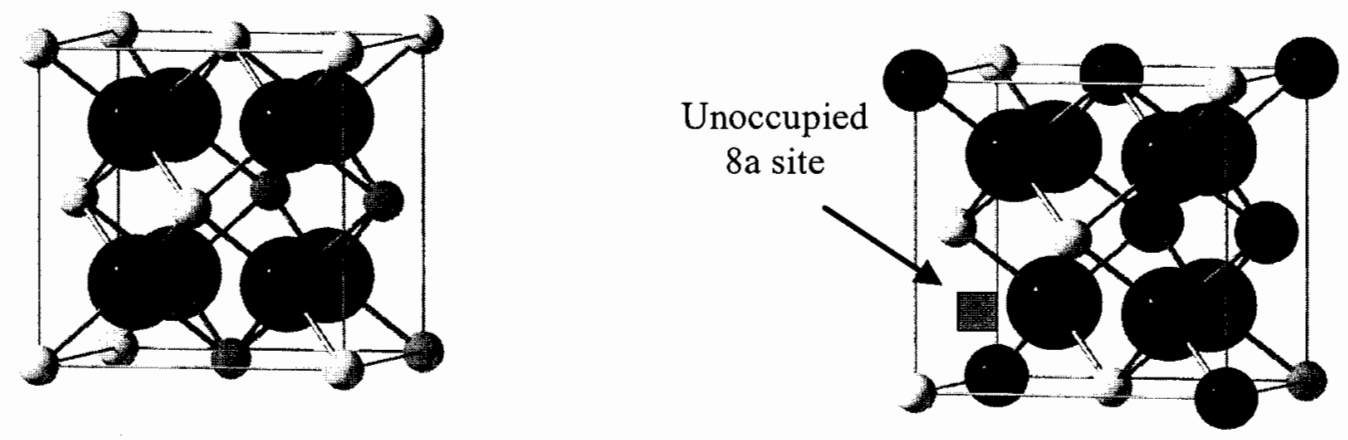

Figure 12. (Left) Unit cell of the fluorite crystal structure $\left(\mathrm{BO}_{2}\right)$ containing four $\mathrm{B}$ cations (yellow) and eight oxygen anions (red). (Right) One-eighth of the unit cell of the pyrochlore structure $\left(\mathrm{A}_{2} \mathrm{~B}_{2} \mathrm{O}_{7}\right)$ with A cations shown in blue. Notice the oxygen 8 a vacant position.

Due to their structural compatibility with large ions such as the actinide series, pyrochlores have been extensively studied in the past for nuclear applications but mainly as storage matrices. 0 More 
recently however, pyrochlores have been identified as promising candidates for IMF. For example, Raison and Haire have shown that for similar concentrations of actinides (e.g., $30 \mathrm{~mol} \%$ of $\mathrm{AmO}_{2}$ ), $\mathrm{An}_{2} \mathrm{Zr}_{2} \mathrm{O}_{7}$ pyrochlores (where $\mathrm{An}=\mathrm{Am}, \mathrm{Np}$ or $\mathrm{Pu}$ ) can be successfully employed as a host matrix for transmutation and will contain higher amounts of actinide for the same unit volume (i.e., higher volumetric efficiency) when compared with the $\mathrm{ZrO}_{2}$ host matrix.0 Furthermore, Lutique et al. have recently investigated both theoretical and experimentally the potential of neodymium zirconate pyrochlore $\left(\mathrm{Nd}_{2} \mathrm{Zr}_{2} \mathrm{O}_{7}\right)$ as a transmutation target. 0 While, it was concluded that the thermal conductivity of $\mathrm{Nd}_{2} \mathrm{Zr}_{2} \mathrm{O}_{7}$ is too low to be used as a single phase $\mathrm{IMF}$, it was also shown that the expected temperature profiles of a $\mathrm{MgO}-\mathrm{Nd}_{2} \mathrm{Zr}_{2} \mathrm{O}_{7}$ cercer composite IMF pellet would be lower than the corresponding profile for $\mathrm{UO}_{2}$ making the composite approach extremely appealing. Ongoing research by Lutique et al on irradiation behavior of $\mathrm{Nd}_{2} \mathrm{Zr}_{2} \mathrm{O}_{7}$ has shown good resistance to $120 \mathrm{MeV}$ iodine ion irradiation with no amorphization, no swelling and with minimal impact on the central temperature. 0

The above results are very promising and serve as a motivation for further experimental and computational research towards the optimization of composition and microstructure of oxide pyrochlore composites for IMF.

In choosing the pyrochlore material for the next generation IMF MgO based composites, four main down-selecting criteria are employed: irradiation stability, thermal conductivity, neutron capture and hot water corrosion resistance.

Atomic-level simulation of the irradiation stability and thermal conductivity of pyrochlores was the first step in the down-selection process. As shown in Figure 13, experiments and atomic-level simulation have shown that $\mathrm{Ln}_{2} \mathrm{Zr}_{2} \mathrm{O}_{7}$ pyrochlores are much more radiation tolerant than $\mathrm{Ln}_{2} \mathrm{Ti}_{2} \mathrm{O}_{7}$ pyrochlores $(\mathrm{Ln}=$ La, La, Pr, Nd, Sm, Eu Gd, Y).0

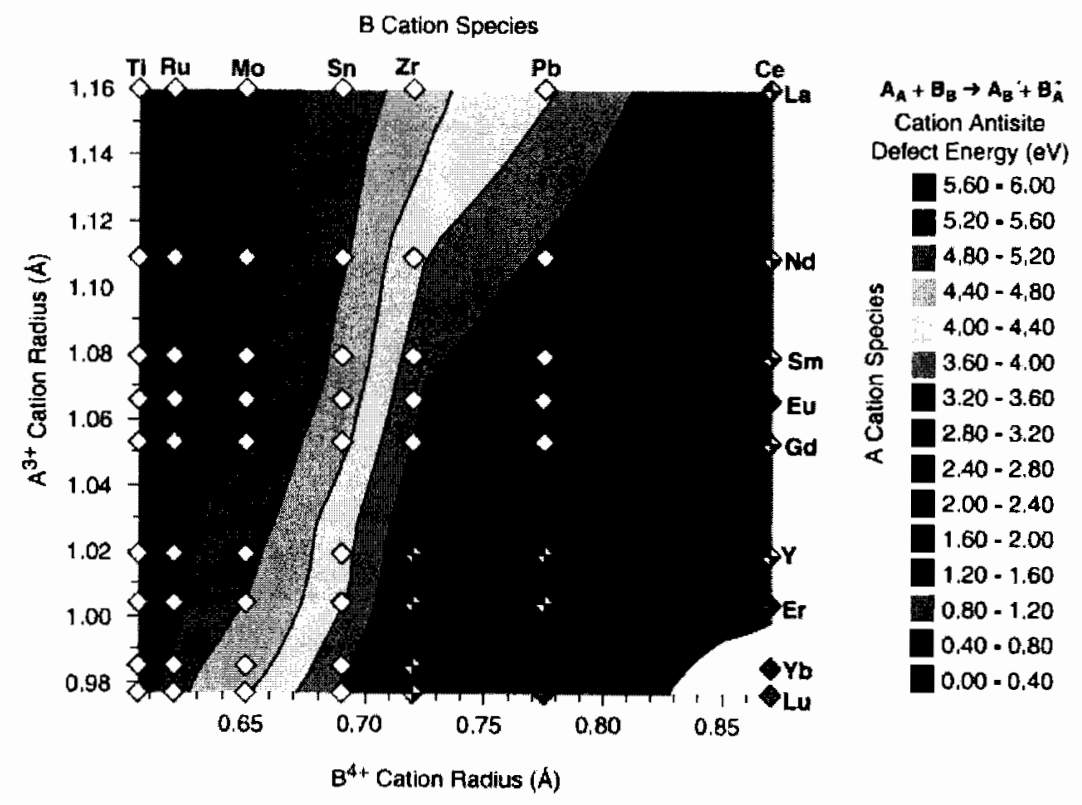

Figure 13. Experiment and atomistic simulations show that increasing the $\mathrm{B}$ cation radius lowers the antisite defect energy and, hence, decreases the amount of radiation damage. The $\mathrm{Pb}$ and $\mathrm{Ce}$ pyrochlores are not stable, indicating that the $\mathrm{Ln}_{2} \mathrm{Zr}_{2} \mathrm{O}_{7}$ systems are optimal. (K. E. Sickafus, L. Minervini, R. W. Grimes, J. A. Valdez, Science 289, 748 (2000)). 
Using exactly the same atomistic potentials Schelling et al. have calculated thermal conductivity maps for these pyrochlores Figure 14.0 It can be seen that within the $\operatorname{Ln}_{2} \mathrm{Zr}_{2} \mathrm{O}_{7}$ systems there is little thermal conductivity variation. Therefore, pyrochlore composition can be optimized for irradiation and corrosion without heavily impacting the thermal conductivity of the IMF.

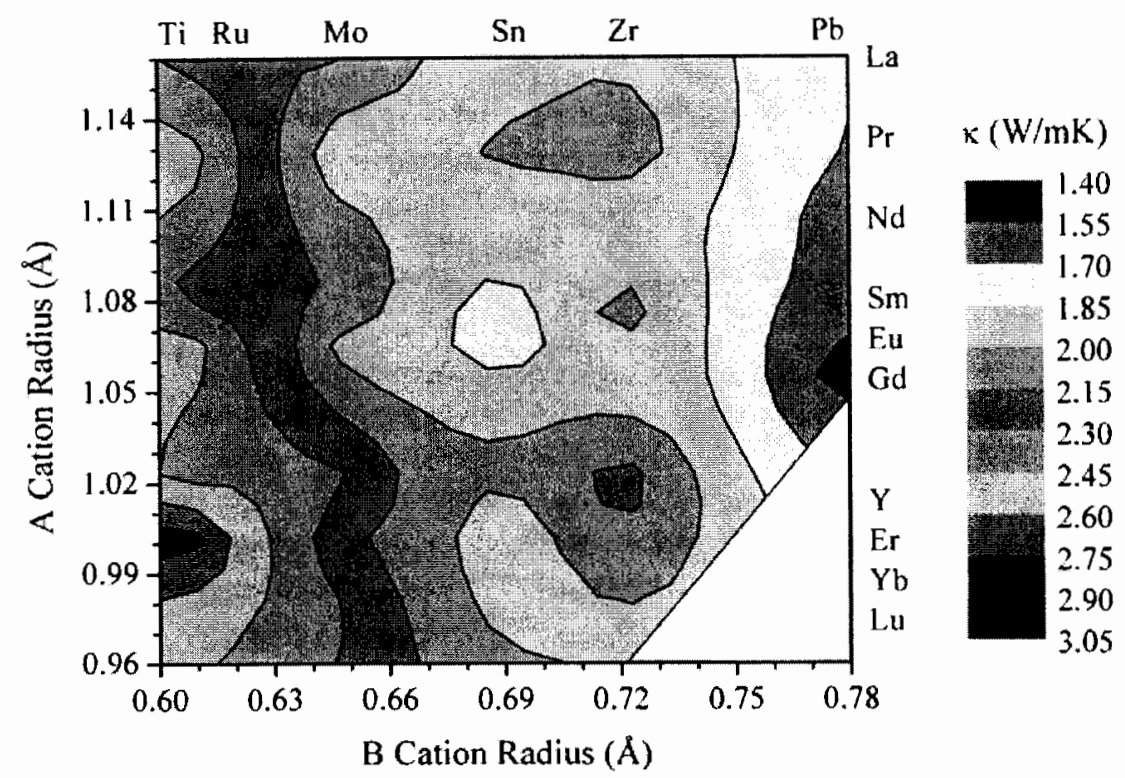

Figure 14. Calculated thermal conductivity map for forty different $\mathrm{A}_{2} \mathrm{~B}_{2} \mathrm{O}_{7}$ pyrochlores. (P. K. Schelling, S. R. Phillpot and R. W. Grimes, Phil. Mag. 84, 127 (2004)).

From a neutronics point of view, of the rare earth elements considered, $\mathrm{Nd}$ and $\mathrm{Yb}$ have the smallest cross section to neutron absorption (50.5 b and $34.8 \mathrm{~b}$, respectively). Therefore, $\mathrm{Nd}_{2} \mathrm{Zr}_{2} \mathrm{O}_{7}$ and $\mathrm{Yb}_{2} \mathrm{Zr}_{2} \mathrm{O}_{7}$ are the selected zirconate pyrochlore compositions for $\mathrm{MgO}$-pyrochlore cercer IMF.

These selected compounds are currently being synthesized at University of Florida (UF) by conventional solid-state processing. Slurries of reagent grade starting oxides are ball-milled to ensure proper mixing. Resulting mixtures are dried to form powders which are calcined to form powders of the pyrochlore phases. Pyrochlore formation is verified by $\mathbf{X}$-ray diffraction. Following the calcination step, pyrochlore powders are once again ball-milled, dried and sieved to obtain fine homogenous pyrochlore powders with control particle size distribution. Following separate calcinations of $\mathrm{MgCO}_{3}$ precursor, the resulting $\mathrm{MgO}$ powder is added to the pyrochlore compounds to form two phase mixtures with different volume fractions. The resulting powders (MgO-pyrochlore composite) are compacted to form pellets using an isostatic press in order to achieve maximum "green" density. Pellets are then sintered in tube and box furnaces under different atmosphere and temperature conditions for densification, phase redistribution and grain growth control. The sintered pellet is then examined for phase purity using $\mathrm{X}$-ray diffraction, microstructure and composition (grain size, phase distribution, grain boundaries, etc.) using scanning electron microscopy (SEM) and energy dispersive x-ray spectrometry (EDS). The ideal processing conditions and thermal treatment resulting in optimum sintering and final microstructure are then determined.0

Furthermore, since the IMF consists of both the pyrochlore phase and the MgO phase. Computational simulations are currently being performed to identify the $\mathrm{MgO}$-pyrochlore composite connectivity and phase distribution providing optimum thermal conductivity. Microstructures to be 
explored will range from 0-3 composites, in which the pyrochlore is embedded in an $\mathrm{MgO}$ matrix, to 3-3 composites, in which both the $\mathrm{MgO}$ and pyrochlore phases are continuous. Thermal conductivities of these composite configurations are being simulated using standard analytical approaches.

The high temperature $(\sim 1300 \mathrm{~K})$ thermal properties of the UF-synthesized IMF materials will be measured at INL using a laser flash apparatus. Laser Flash techniques enable measurement of thermal diffusivity and heat capacity of materials. These experimental results will help refine the simulation models which, in turn, will allow the simulations to better guide future experiments.

Along with the thermophysical characterization the hot water corrosion resistance of the $\mathrm{MF}$ candidate materials will be tested by placing the sintered ceramic pellets in an autoclave to expose the materials to water at $300^{\circ} \mathrm{C}$ and $9 \mathrm{MPa}$ for extended periods of time. During the process, periodic inspections of the pellets will be performed. Pellets will be checked for weight change, surface hydration, cracking, grain pull out and grain boundary deterioration using optical microscopy, SEM and EDS. Based on the results, the microstructure of the pellets will be optimized by tuning the synthesis and sintering conditions in order to improve the corrosion resistance. 0

Once we have identified, synthesized, characterized and optimized the best $\mathrm{MgO}$-pyrochlore candidates for IMF, Samantha Yates (University of Florida graduate student) will visit INL to incorporate $\mathrm{PuO}_{2}$ into these compounds. The student will synthesize and characterize the thermophysical properties of Pu-bearing IMF compounds.

The most promising compounds from the thermophysical, neutronics, and corrosion resistance point of view will be incorporated in the LWR-2 irradiation test in the Advanced Test Reactor.

\subsection{Zr Metal Inert Matrix Dispersion Fuel Development}

$\mathrm{Zr}$ metal inert matrix dispersion fuels offer another novel approach to fulfilling the fuel requirements for a TRU burning fuel in current and advanced LWR. Like many of the ceramic matrix based IMF fuels thermal conductivity is a major concern. In this regard $\mathrm{Zr}$ metal works well having a thermal conductivity at least as good as and in many cases better than most ceramic materials. This fuel form will also provide flexibility in the amount and composition of fuel phase that can be incorporated based on thermal and neutronic calculations. As noted in earlier sections in order to achieve adequate reactor control a burnable poison may need to be incorporated. It is currently anticipated that incorporation of a burnable poison into this fuel form will not present any significant fabrication issues. Currently fabrication research has been carried out at the Idaho National Laboratory using $\mathrm{ZrO}_{2}$ spheres as a surrogate fuel phase. Preparations are being made to carry out this work with enriched uranium as the fuel phase for possible inclusion in the LWR-2 irradiation test. This section will cover the fabrication work done up to this point in particular in regards to matrix fabrication/consolidation however, $\mathrm{UO}_{2}$ particle production will be discussed as well.

The basic fabrication route is quite simple a mixture or fuel particles and powdered zirconium are compacted into a hollow zirconium alloy (Zircaloy-4 is currently being used) billet. An additional amount of non-fueled zirconium or Zircaloy is compacted on top of the fueled section and the entire billet is then sealed in a copper can. The assembly is then extruded to a smaller diameter providing both consolidation of the matrix and fuel phase and bonding between all of the components. The following paragraphs will address these basic steps in more detail and give results of the on going development.

A cylindrical Zircaloy-4 (Zr-4) billet was fabricated by drilling out the center portion and tapering the front. This billet was then filled with zirconium powder and approximately 30 volume $\% \mathrm{ZrO}_{2}$ spheres with the top portion being filled only with zirconium powders with no spheres. Figure 15 shows a basic 
schematic of the prepared assembly, the assembly was then sealed in a copper can. The copper can provides both lubrication during extrusion and oxidation protection for the zirconium during heating and extrusion. A simple extrusion die was fabricated with a reduction from approximately 1 in. reduced to 0.4 in. (area reduction ration of approximately $6: 1$ ). The sealed assembly was placed in the die and the die heated to $750^{\circ} \mathrm{C}$ and allowed to soak approximately two hours. After soaking the die was moved to a large platen press which serves as a extrusion press and pressure was applied. The resulting extrusion was approximately 2 in. long, Figure 16.

Earlier extrusion attempts have been made using the same process, however, the reduction was from 0.685 in. to 0.25 in. (area reduction ratio of $7.5: 1$ ) and niobium coated spheres were used. This extrusion attempt was also successful with approximately 4 in. of extruded material.

The niobium coating will be necessary on the final fuel to prevent interaction between the zirconium metal and uranium oxide. Traditional such coatings are applied through fluidized bed chemical vapor deposition. The coating used in these studies was applied following a powder metallurgical approach. The spheres and the powder were both well coated with a binder and placed in a rotating tumbler which contacted the two materials. The result was a very porous coating which could then be sintered. Although the sintered coating was very porous after sintering the extrusion process densified the coating to fully dense as seen under optical microscopy.

The extruded portion of the sample was characterized using optical microscopy. The matrix was fully dense and "fuel" particles mostly uniformly distributed throughout the interior, Figure 17. Also as can be seen from Figure 17 the $\mathrm{Zr}-4$ billet is very well bonded to the zirconium matrix with no voids being visible. In some areas it is visible that the spheres extruded into the cladding material, reducing the cladding thickness. Also behind some spheres a pore exists due to matrix material flow around the particles.

Neither the pore behind the sphere nor the reduced cladding thickness poses a significant challenge. One of the main advantages of the dispersion fuel is the fact that the fission product recoil damage is limited to a small volume of material. Even with these scattered pores this advantage is still in place. Also because the matrix is fully dense all fission gases will remain contained. Through the extrusion runs it has been observed that the spheres do not extrude into the cladding more than one-half of the diameter of the fuel sphere. This amount of reduced thickness can be compensated for by having a slightly larger cladding thickness, a reduced fuel sphere diameter, or it may also be improved by better extrusion parameter control.

Although not incorporated into the extrusion deplete $\mathrm{UO}_{2}$ spheres have been fabricated through rotating electrode atomization. In this process a feed pellet of $\mathrm{UO}_{2}$ is rotated at approximately 7000-10000 RPM and brought through an electric arc. The electric arc heats the material to melting and small droplets are flung off forming spheres before solidification. Figure 18 shows an example of the particles produced. As seen the particles are very spherical. The size distribution is uni-modal with one narrow peak. This peak can be moved to smaller or larger particle sizes based on the rotational velocity, higher velocities produce smaller particles. Sphere cross sections show a large shrinkage void in the interior of most spheres.

In conclusion a Zircaloy- 4 clad sample has been extruded with a zirconium matrix and zirconium oxide as a surrogate fuel phase. This has shown promise that a fuel bearing sample suitable for irradiation testing could be produced with little modification to the system. The zirconium matrix will contain the fission gases and, as a dispersion fuel, will have those attractive attributes to a dispersion fuel. Of these attributes one of the most important is the bulk of the matrix is not affected by fission fragment damage, therefore, properties such as thermal conductivity is not as severely degraded. Therefore the higher 
thermal conductivity of zirconium metal will lower the overall fuel temperature allowing for better fuel performance. Also similar dispersion fuels utilizing stainless steel as a matrix have been shown to be very robust, therefore as an actinide burning fuel form high actinide burning will be achievable. Although not traditional, spherical fuel particles have also been produced through rotating electrode atomization. These particles are uniform in size although a shrinkage void is present in the interior.

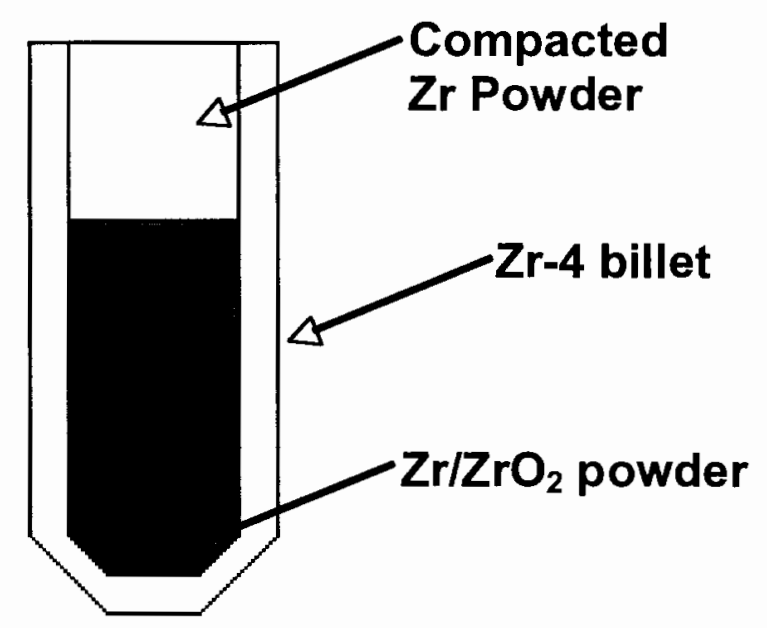

Figure 15. Schematic representation of the assembled $\mathrm{Zr}-4 / \mathrm{Zr}$ billet.

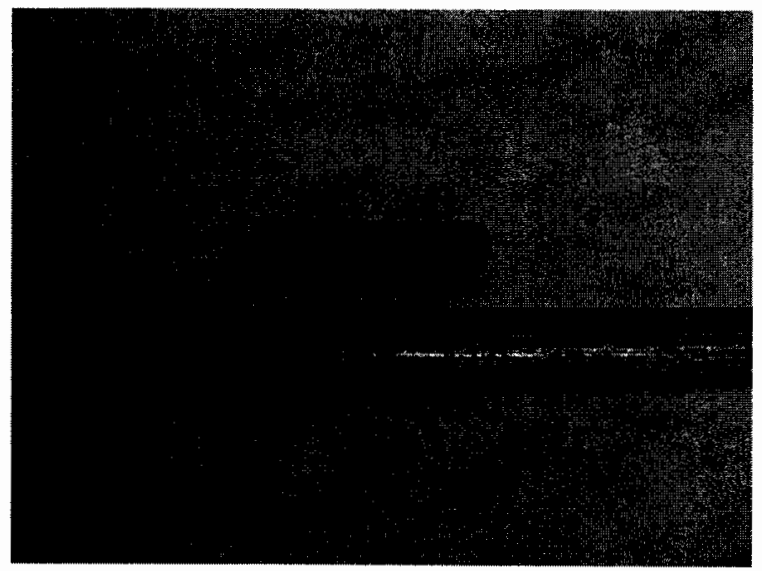

Figure 16. Photograph of 0.4-in. diameter Zr matrix dispersion "fuel" extrusion. 


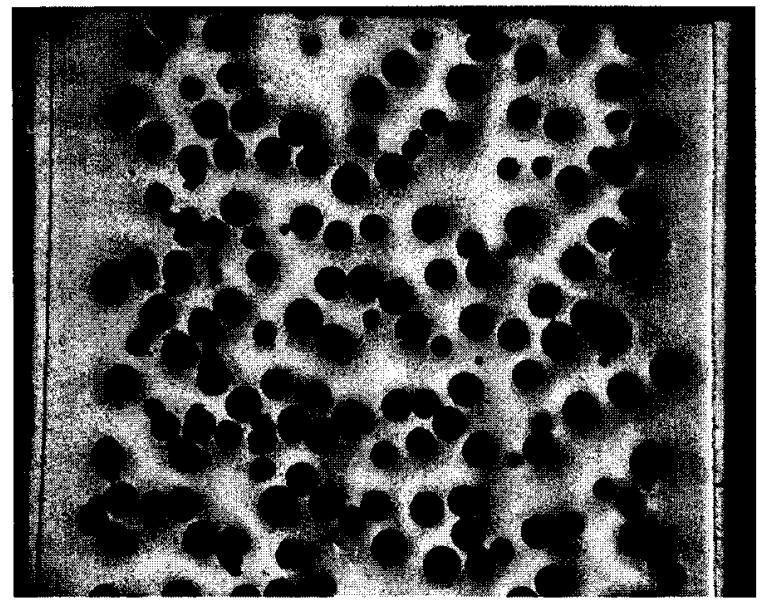

Figure 17. Photograph of 0.4-in. diameter $\mathrm{Zr}$ matrix dispersion "fuel" extrusion longitudinal cross section. Spheres measure approximately $0.5 \mathrm{~mm}$ in diameter.

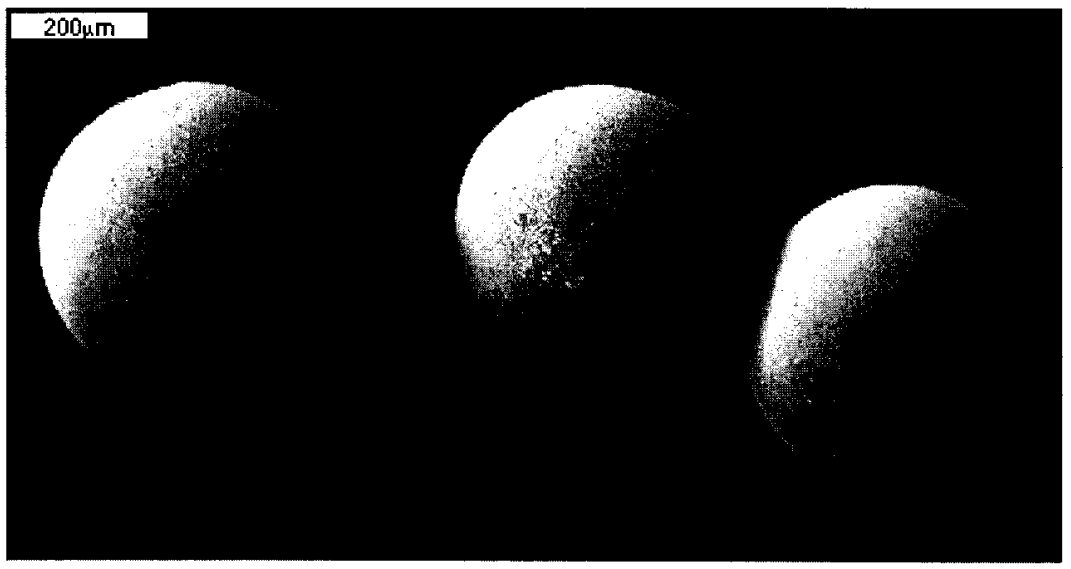

Figure 18. $\mathrm{UO}_{2}$ spheres produced through rotating electrode atomization. 


\section{REFERENCES}

1. G.S. Chang and J.M. Ryskamp, Nuclear Technology, 129, March 2000.

2. J.S. Herring, P.E. MacDonald, and K.D. Weaver, Nuclear Technology, 147, July 2004.

3. S. Eaton, C. Beard, K. Ramsey, J. Buksa, and K. Chidester, Nuclear Science and Engineering, 136, 2000, pp. 151-177.

4. Schram, et al., Progress in Nuclear Energy, 38, No. 3-4, 2001, pp. 259-262.

5. G. Ledergerber, C. Degueldre, P. Heimgartner, M.A. Pouchon, U. Kasemeyer, Progress in Nuclear Energy, 38, No. 3-4, 2001, pp. 301-308.

6. P. Medvedev, "Fabrication and characterization of magnesia-zirconia-plutonia ceramics." E-MRS, IMF-10, Strasbourg, France, May 2005.

7. P. Medvedev, "Development of Dual Phase Magnesia-Zirconia Ceramics for Light Water Reactor Inert Matrix Fuel," Dissertation, Texas A\&M University, December 2004.

8. J. Porta and M. Asou, Progress in Nuclear Energy, 38, No. 3-4, 2001, pp. 347-350.

9. C. Hellwig, U. Kasemeyer, G. Ledergerber, B. Lee, Y-W Lee, R. Chawla, Annals of Nuclear Energy, 30, 2003, pp. 287-299.

10. M. Todosow, M. et al., Initial Report on Safety and Licensing Issues Associated with the use of Inert Matrix Fuels in Light-Water Reactors (LWRs). Brookhaven National Laboratory Report: BNL-AFCI-2004-002, November, 2004.

11. J. M. Paratte, K. Foskolos, P. Grimm, C. Maeder, "The PSI Code System ELCOS for LWR Core Analysis", Paul Scherrer Institute, Villigen PSI, February 1996.

12. COBRA-EN: Code System for Thermal-Hydraulic Transient Analysis of Light Water Reactor Fuel Assemblies and Cores, PSR-507, RSICC, ORNL, May 2001.

13. RELAP5-3D Code Manual Volume 1: Code Structure, System Models and Solution Methods, INEEL-EXT-98-00834, Revision 2.2, October 2003.

14. Westinghouse Nuclear Energy Systems, "Safety Analysis Report (RESAR-41)," December 1973.

15. K.E. Sickafus, R.J. Hanrahan, K.J. McClellan, J.N. Mitchell, C.J. Wetteland, D.P. Butt, P. Chodak, K.B. Ramsey, T.H. Blair, K. Chidester, H. Matzke, K. Yasuda, R.A. Verrall, N. Yu, "Burn and bury option for plutonium," Am. Cer. Soc. Bull. 78 (1), 1999, pp.69-74.

16. Ch. Hellwig and U. Kasemeyer, Inert matrix fuel performance during the first two irradiation cycles in a test reactor: comparison with modeling results, Journal of Nuclear Material, 319, 2003, pp. 87-94

17. T. Nakamura, H. Sasajima, T. Yamashita and H. Uetsuka, Morphology change of rock-like oxide fuels in reactivity-initiated-accident simulation tests, Journal of Nuclear Material, 319, 2003, pp. 95-101. 
18. C. Degueldre, J. Paratte, "Basic properties of a zirconia-based fuel material for light-water reactors," Nuclear Technology, 123 (1), 1998, pp. 21-29.

19. C. Degueldre, T. Arima, Y. W. Lee, "Thermal conductivity of zirconia based inert matrix fuel: use and abuse of the formal models for testing new experimental data," Journal of Nuclear Material, 319,2003 , pp. 6-14.

20. K. Yasuda, C. Kinoshita, S. Matsumura and A. I. Ryazanov, "Radiation-induced defect clusters in fully stabilized zirconia irradiated with ions and/or electrons," Journal of Nuclear Material, 319, 2003, pp. 74-80.

21. U. Kasemeyer, Ch. Hellwig, J. Lebenhaft and R. Chawla, "Comparison of various partial lightwater reactor core loadings with inert matrix and mixed-oxide fuel," Journal of Nuclear Material, 319, 2003, pp. 142-153.

22. H. Akie, Y. Sugo and R. Okawa, "Core burnup calculation and accidents analyses of a pressurized water reactor partially loaded with rock-like oxide fuel," Journal of Nuclear Material, 319, 2003, pp. 166-172.

23. S. Lutique, R.J.M. Konings, V.V. Rondinella, J. Somers, T. Wiss, "The thermal conductivity of $\mathrm{Nd} 2 \mathrm{Zr} 2 \mathrm{O} 7$ pyrochlore and the thermal behavior of pyrochlore-based inert matrix fuel," Journal of Alloys and Compounds, 352, 2003, pp. 1-5.

24. P.G. Medvedev, "Development of dual-phase magnesia-zirconia ceramics for light-water reactor inert matrix fuel," Dissertation, Texas A\&M University, 2004.

25. P. G. Mardon, D. J. Hodkin, J. T. Dalton, "Some observations on the Pu-Zr-O system," Journal of Nuclear Material, 32, 1969, pp. 126-134.

26. W. J. Weber, J. W. Wald, H. Matzke, Journal of Nuclear Materials, 138, 1986, pp. 196-209.

27. H. Kamizono, I. Hayakawa, S. Muraoka, Journal of the American Ceramic Society, 74, 1991, pp. 863-864.

28. I. Hayakawa, H. Kamizono, Journal of Nuclear Materials, 202, 1993, pp. 163-168.

29. G. R. Lumpkin, K. P. Hart, P. J. Mcglinn, T. E. Payne, R. Giere, C. T. Williams, Radiochimica Acta, 66-7, 1994, pp. 469-474.

30. K. P. Hart, G. R. Lumpkin, R. Giere, C. T. Williams, P. J. McGlinn, T. E. Payne, Radiochimica Acta 74 (1996) 309-312.

31. P. E. Raison, R. G. Haire, Progress in Nuclear Energy, 38, 2001, pp. 251-254.

32. S. Lutique, R. J. M. Konings, W. Rondinella, J. Somers, T. Wiss, Journal of Alloys and Compounds, 352, 2003, pp. 1-5.

33. S. Lutique, D. Staicu, R. J. M. Konings, V. V. Rondinella, J. Somers, T. Wiss, Journal of Nuclear Materials, 319, 2003, pp. 59-64.

34. K. E. Sickafus, L. Minervini, R. W. Grimes, J. A. Valdez, M. Ishimaru, F. Li, K. J. McClellan, T. Hartmann, Science, 289, 2000, pp. 748-751. 
35. P. K. Schelling, S. R. Phillpot, R. W. Grimes, Philosophical Magazine Letters, 84, 2004, pp. 127 137.

36. J. C. Nino, M. T. Lanagan, C. A. Randall, Journal of Materials Research, 16, 2001, pp. 1460-1464.

37. J. Payapilla, D. P. Butt, Journal of Nuclear Material,. (submitted 2004). 